\title{
Social vulnerability projections improve sea-level rise risk assessments
}

\author{
R. Dean Hardy ${ }^{1,2}$ and Mathew E. Hauer ${ }^{1}$ \\ ${ }^{1}$ Department of Geography, University of Georgia \\ ${ }^{2}$ Corresponding author's present address: National Socio-Environmental Synthesis Center, \\ University of Maryland College Park, dhardy@ sesync.org
}

\begin{abstract}
Rising seas will impact millions of coastal residents in coming decades. The vulnerability of coastal populations exposed to inundation will be greater for some sub-populations due to differences in their socio-demographic characteristics. Many climate risk and vulnerability assessments, however, model current populations against future environments. We advance sealevel rise risk assessments by dynamically modeling environmental change and sociodemographic change. We project three scenarios of inundation exposure due to future sea-level rise in coastal Georgia from 2010 to 2050. We align the sea-level rise projections with five population projection scenarios of socially vulnerable sub-populations via the Hamilton-Perry method and the theory of demographic metabolism. Our combined fast sea-level rise and middle population scenarios project a near doubling of the population exposed, and a more than fivefold increase for those at risk (i.e., residing in a census tract with high social vulnerability) and most at risk (i.e., high social vulnerability and high exposure) compared to the same estimate based on 2010 population data. Of vulnerable sub-populations, women had the largest absolute increase in exposure for all scenario combinations. The Hispanic/Latinx population's exposure increased the largest proportionally under the fast and medium sea-level rise projections and elderly people's $\left(65^{+}\right)$under the slow sea-level rise scenario. Our findings suggest that for coastal areas experiencing rapid growth (or declines) in more socially vulnerable subpopulations, estimates based on current population data are likely to underestimate (or overestimate) the proportion of such groups' risk to inundation from future sea-level rise.
\end{abstract}

\section{Keywords}

social vulnerability; risk assessment; sea-level rise; demographic metabolism; climate change, Georgia

\section{Acknowledgements}

This work was partially supported by the National Science Foundation [Award \#1458978, 20152017] and via Research Assistantships provided by the University of Georgia Graduate School and the University of Georgia Integrative Conservation PhD Program. Support for revisions was provided through a Postdoctoral Fellowship with the National Socio-Environmental Synthesis Center [NSF Award \# DBI-1052875]. We thank Marguerite Madden, Nate Nibbelink, Marshall Shepherd, and several anonymous reviewers for feedback on earlier versions of the article. 


\section{Introduction}

Global mean sea level is forecast to rise by as much as $2 \mathrm{~m}$ or more this century (Vermeer and Rahmstorf 2009; Kopp et al. 2014, 2017; DeConto and Pollard 2016; Sweet et al. 2017). By 2060 , as much as $12 \%$ of the global population - 1.4 billion people - could live in the low elevation coastal zone, many with the sustainability of their livelihoods linked to coastal environments (Neumann et al. 2015). Under equal exposure to climate change hazards, however, the vulnerability of some coastal sub-populations will be much greater due to differences in their socio-economic characteristics (Gaillard et al. 2014; Shepherd and KC 2015; Jurgilevich et al. 2017; Lutz and Muttarak 2017; Otto et al. 2017). Numerous case studies support the connections between increased vulnerability to environmental hazards and multiple socio-economic characteristics including non-white racial and non-Hispanic ethnic groups, women, people with low educational attainment or living in poverty, and both the young and elderly, as well as many other socio-economic factors (Bullard 1990; Bolin, Jackson, and Crist 1998; Ngo 2001; Wisner et al. 2004; Bolin 2007; Neumayer and Plümper 2007; Wailoo 2010; Rufat et al. 2015; Shepherd and $\mathrm{KC} 2015)$. This suggests that assessing the risk of the most vulnerable coastal populations to inundation exposure from sea-level rise is increasingly important for improving coastal adaptation planning and policies. In this article, we define risk as a function of vulnerability, exposure, and hazard (see Jurgilevich et al. 2017).

Many climate risk and vulnerability assessments, however, model current populations against future environments (e.g., Frazier et al. 2010; Emrich and Cutter 2011; Martinich et al. 2013; Shepherd and KC 2015; Kopp et al. 2017; Kulp and Strauss 2017; Spanger-Siegfried et al. 2017). This approach renders methods for assessing future climate risk as both static (population) and dynamic (environmental change). Only recently have studies of sea-level rise impacts started 
accounting for population change simultaneously with the associated environmental change expected from inundation (Neumann et al. 2015; Hauer, Evans, and Mishra 2016; Hauer 2017). These studies are limited to exposure assessments, however, quantifying the total future population expected to be impacted by sea-level rise inundation. They do not account for who that coastal population will be, in other words, its socio-demographic characteristics. Previous studies have compared future inundation exposure against either 1) current socially vulnerable populations, or 2) undifferentiated totals of future populations. Few, if any, have compared future inundation exposure against future projections of socially vulnerable sub-populations. Many of the previous studies have shown that a substantial portion of current coastal populations in the United States have sub-populations with increased levels of social vulnerability. Given this and the well-documented historical growth in US coastal populations (Culliton et al. 2010; Crossett et al. 2013) and its projected future growth (Hauer, Evans, and Mishra 2016), such a temporal misalignment of comparing current social vulnerability against future inundation exposure will likely lead to incorrect estimates of the future risk of coastal populations.

The temporal misalignment in previous studies is due to limited methodological approaches for analyzing gradual environmental change in concert with multi-decadal sociodemographic change (Jurgilevich et al. 2017). Recent theoretical developments in demography, however, offer an approach for overcoming this shortcoming through a multi-dimensional predictive model of socio-demographic change called demographic metabolism (Lutz 2013; Lutz and Muttarak 2017). Specifically designed for climate change research, demographic metabolism is a theoretical framework that argues that "the process of social change can be analytically captured through the process of younger cohorts replacing older ones" (Lutz 2013, 284). The cohort aged 15-19 in 2015 becomes the 20-24 cohort in 2020 after adjusting for the components 
of population change: births, deaths, and migration. This approach creates reliable sociodemographic forecasts over decadal time scales for two key reasons: 1) many socio-demographic characteristics are either established at a young age (e.g., the proportion of people with a high school education aged 25-29 in 2015 is a good predictor of those aged 60-64 with a high school education in 2050) (Lutz and KC 2011), and 2) socio-demographic change is embedded within the age structure (e.g., life course analysis shows that earnings steadily increase after age 18, peaking around age 65, before declining through retirement) (Tamborini, Kim, and Sakamoto 2015).

In this article, we advance sea-level rise risk assessments by dynamically modeling environmental change and socio-demographic change of coastal populations. Specifically, we forecast inundation exposure due to future sea-level rise along with projections of the sociodemographic indicators of social vulnerability for populations in coastal Georgia. Given the high projections of US coastal population growth (Hauer, Evans, and Mishra 2016), we examine the potential underestimation of previous estimates of social vulnerability to sea-level rise. We assess the total and proportional change in vulnerable sub-populations at risk to inundation by comparing estimates based on 2010 and 2050 population data. Our analysis allows us to capture the dynamic spatio-temporal relationship between shifts in socio-demographic indicators driving social vulnerability and increasing levels of inundation exposure from future sea-level rise.

\section{Methods}

\subsection{Study area}




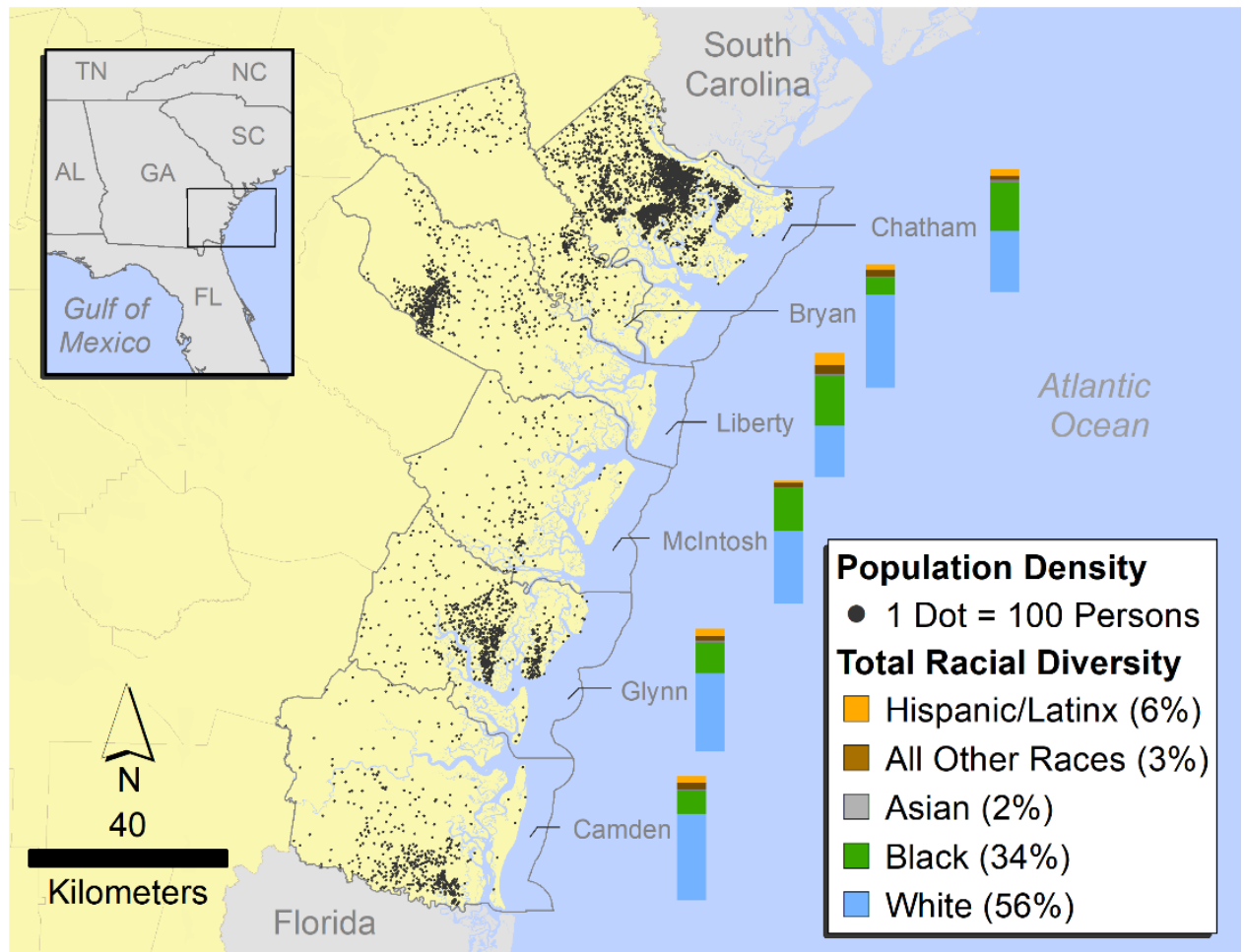

Figure 1. Study site of coastal Georgia. Racial diversity by county and population density for US Census block groups (US Census, 2012). Stacked bars show the current proportion of racial diversity in each county. Block group outlines are not shown for clarity. Dots are restricted to land only. [1.5 columns]

We selected coastal Georgia in the United States as our study area given its rural-to-urban settings and diverse demographics including relatively high numbers of people with the characteristics that are indicated to increase social vulnerability (Figure 1) (Cutter, Boruff, and Shirley 2003; Wisner et al. 2004). Of the greater than 500,000 people residing in the six coastal county region, roughly $227,000(44 \%)$ are racial and/or ethnic minorities, approximately 87,000 (18\%) are living in poverty, and over 38,000 (11\%) of those 25 years and older have less than a high school equivalent educational attainment level (US Census 2012). Coastal Georgia's current population that could be exposed to inundation from sea-level rise of $0.9-1.8 \mathrm{~m}$ by the year 2100 is estimated to be between approximately 51,000 and 96,000, respectively (Hauer, Evans, and Mishra 2016). The exposed population is expected to nearly double when accounting for Georgia's population growth to between approximately 93,000 and 179,000 people by the year 2100 (Hauer, Evans, and Mishra 2016). Studies based on 2010 US Census population data 
estimate that there are approximately 5,000 Georgia residents with high social vulnerability living within $0.9 \mathrm{~m}$ of the high tide line (Strauss et al. 2014). Taking into account the significant population growth projected for the region, however, it is likely that the socially vulnerable population of the future will be much greater. Moreover, being able to identify and quantify whom those socially vulnerable populations will be is of critical importance for targeting adaptation planning and policies at vulnerable sub-populations.

\subsection{Population projections}

One of the most well-accepted approaches for projecting populations is the cohortcomponent method, which uses migration, birth, and death rates to forecast population changes within an area (Smith, Tayman, and Swanson 2001). Given the difficulty of obtaining these data for some areas and smaller geographies such as US Census tracts, a simpler approach was proposed, known as the Hamilton-Perry method, which uses cohort-change ratios (CCR) between the two most recent census counts to project populations by age and sex, and sometimes race or ethnicity (Hamilton and Perry 1962; Swanson, Schlottmann, and Schmidt 2010). Using the Hamilton-Perry method based on 2000-2010 US Census data and a series of controlling factors and limits, we projected populations by age, sex, race, and ethnicity in 10-year cohorts from 2010 to 2050 at both the county $(n=6)$ and census tract levels $(n=121)$ for the Georgia coast following:

$$
{ }_{n} \mathrm{CCR}_{x}=\frac{{ }_{n} P_{x+y, l}}{{ }_{n} P_{x, b}}
$$

where $n$ is the cohort interval, $x$ is the starting age of the cohort, ${ }_{n} P_{x+y, l}$ is the population aged $x+$ $y$ to $x+y+n$ in the most recent census $(l),{ }_{n} P_{x, b}$ is the population aged $x$ to $x+n$ in the second most recent census $(b)$, and $y$ is the number of years between the two censuses $(l-b)$ according to Smith et al. (2001). 
Given the 10-year interval of most US Census data, the age cohort of 10-19 is the minimum for applying the CCR. Child-woman ratios (CWR) are used to project populations of the 0-9 age cohort. We made two adjustments to Smith et al.'s (2001) recommendation for assessing CWRs. First, we used 10-year age cohorts instead of five-year age cohorts because our projection interval was 10 years. Second, we assessed the combined CWR for the population of male and female children due to low counts for some groups. We calculated CWRs for the launch year's population by calculating the ratio of children aged 0-9 to women aged 15-49 following:

$$
\text { Children aged } 0-9:{ }_{10} P_{0, t}=\frac{{ }_{10} P_{0, l}}{{ }_{35} P_{15, l}},
$$

We divided this combined CWR by two before calculating the projected target population of male and female children, which assumes an equal birth rate for the sexes. As we projected in 10-year age cohorts over 10-year periods, we used half of the $10-19$ aged female population count to ascertain the number of women 15-19 to be included in the 35-year window in equation Eq. (2).

Two challenges emerge when projecting populations for sub-county geographies such as census tracts (Swanson, Schlottmann, and Schmidt 2010). A common challenge is the frequent changes that occur with boundaries between census collection years. To overcome this first challenge, we applied the Longitudinal Tract Database's conversion tool (Logan, Xu, and Stults 2014) to each 2000 census tract data table to normalize the data to 2010 census tract boundaries. Another common challenge is specific to the Hamilton-Perry method, which can lead to forecast errors and upward bias in rapidly growing areas (Smith, Tayman, and Swanson 2001). This is due to small populations, particularly those that result in small denominators in the CCR calculation. For example, a cohort (e.g., Asian women 10-19) with a tract population of 10 for 
the base year and 100 for the launch year will have a CCR of 10, leading to a population of one million after only four projection periods. This is less of an issue with larger geographies like counties, but can significantly affect results for smaller geographies such as tracts. Consequently, projections must be controlled to independent projections or projections for larger geographies, such as counties, to overcome these errors (Swanson, Schlottmann, and Schmidt 2010; Baker et al. 2017). The county level projections served as our top-down projections for controlling of the tract level projections.

\subsubsection{County level projections}

We first projected age-sex cohort populations at the county scale using CCR and CWR as described in Eq. (1) and Eq. (2). We then projected age-sex-race-ethnicity (ASRE) cohort populations at the county scale using CCR and CWR, but also applied a single-dimensional raking to control projections for county ASRE cohorts to our county age-sex cohort projections. This ensures that the sum of demographic sub-populations for the ASRE projections equal the independent age-sex projections within counties. Before applying the single-dimensional raking

procedure, we adjusted our uncontrolled projection's CCR for the Hispanic/Latinx population by dividing it by two. This concurs with US Census estimates for a significantly slowed growth rate for this sub-population over our projection period when compared to the 2000 to 2010 rates (Colby and Ortman 2015).

\subsubsection{Tract level projections}

For our initial projections of ASRE cohorts in tract populations, we used the HamiltonPerry method as above, but we applied four controls to our projections. First, we limited the rate of population change for ASRE cohorts by applying the controlled ASRE county projection's race/ethnicity specific CCR. This was necessary to limit some otherwise rapidly growing or 
declining cohorts in some tracts with unusually high CCRs (e.g., over 200). Second, to determine the target year's 0-9 age cohort, we did not use CWRs, but instead controlled this group using implied total fertility rates (iTFR) (Hauer, Baker, and Brown 2013) for race/ethnicity specific groups from the controlled county projections, following:

$$
{ }_{10} P_{0}=10 *\left[\frac{i T F R *{ }_{n} W_{x}}{n}\right]
$$

where subscripts are equal to those in Eq. (2) and ${ }_{n} W_{x}$ equals the total number of women aged $x$ to $x+n$. As with the CWR, we assumed an equal birth rate of both sexes. Third, to limit overly rapid tract population growth or decline we set an annual growth rate ceiling at 1.05 and a floor at 0.98 for all tract projections, which is the same as those set in a previous study that applied the Hamilton-Perry method to sub-county geographies (Swanson et al., 2010). This is especially useful in areas that experienced rapid rates of change between 2000 and 2010 that would be unsustainable over a forty-year period due to build out limitations. Lastly, we used a singleraking procedure (Smith et al., 2001) to adjust all tract population projections to county level ASRE counts to ensure tract level projections summed to county level projections.

\subsubsection{Low education and poverty projections}

To project low educational attainment and poverty, we used 2008-2012 American Community Survey (ACS) US Census data. For low education, ACS Census data are reported as age-sex cohorts of 18-24, 25-34, 45-64, and 65 and above, however, we only assessed low education in populations 25 years and older. Due to our projections being in 10-year cohorts starting with 0-9, we applied a proportional adjustment to our projected population estimate by assuming an equal yearly age distribution among the population for each 10-year age-sex cohort. For example, to calculate the number of women with low education aged 25-34, we divided each of our projected estimates for women aged 20-29 and 30-39 in half and summed the estimated 
25-29 and 30-34 counts. To determine the proportion of the future sex-specific population aged 25 and above with low education, we assumed constant enrollment rates and projected the known rates forward. In other words, we assumed that the low education rates for the tract level age-sex cohorts of 25-34 were frozen at the percentages reported in the 2008-2012 ACS data. For example, the female population aged 25-34 in 2010 would be the female population aged 65-74 population in 2050. By assuming constant enrollment rates, we applied the percentage of the population aged 25-34 in 2010 to each new population that entered this specific age-sex cohort during our projections.

For projecting the population of men and women in poverty, we assumed the agestructure of poverty stayed the same over our projection window. For example, if $10 \%$ of the population aged 20-29 was in poverty in 2010 , then we applied an in poverty rate of $10 \%$ to the population aged 20-29 in all subsequent decades. In other words, we assumed that people moved in and out of poverty as they moved into and out of 10-year age-sex cohorts. This aligns with life course analysis that shows people gain income after age 18 and peak around age 65 before starting to decline again (Tamborini, Kim, and Sakamoto 2015). We acknowledge the uncertainty inherent in ACS data (Spielman, Folch, and Nagle 2014), but contend that our analysis may underestimate poverty rates (Bazuin and Fraser 2013). Our assumption of constant enrollment rates, which assumes "stalled development" is likely an overestimate of the proportion of the future population with low educational attainment (KC and Lutz 2014), however, projecting multiple scenarios of future educational attainment was beyond the scope of this study.

\subsubsection{Population scenarios}

10 | Accepted to Applied Geography on 12/19/2017. Published version: https://doi.org/10.1016/j.apgeog.2017.12.019 
The Hamilton-Perry method is a deterministic approach that assumes that the rate of cohort change over two periods (from 2000 to 2010, in our case) stays constant as the population is projected forward into the future. We developed a suite of scenarios, however, that capture the potential for growth or decline in the total population by varying the rate of change for cohorts. We modeled high and low scenarios of $\pm 5 \%$ and intermediate high and low scenarios of $\pm 1 \%$ for our county level age-sex cohort projections, respectively. For example, if the 20-29 female cohort had a 2000 to 2010 CCR of 1.1 (i.e., $10 \%$ change over the 10 -year period), our high projection scenario would assume a cumulative rate of growth for this cohort of $5 \%$ each period. For the 2020 projection under the high scenario, in other words, we would have multiplied the 2010 population by a CCR of 1.15 for this age-sex cohort. We applied the independent, county level projections as controls for our ASRE county and tract level projections following the approach outlined above.

Our scenario approach assumes a homogenous rate of growth or decline for all cohorts. It does not account for the possibility of some sub-populations to grow at faster rates than others grow (other than that rate which is already accounted for in the non-adjusted CCR). The relative rates of growth among sub-populations, for example, is not altered by our scenarios. In other words, all cohorts' change ratios are either increased or decreased equally. Future iterations of our technique could apply alternative scenarios for specific sub-populations. Such scenario building, however, would require more significant input from local planners and/or expert scenario building based on specific sub-populations' rates of migration, births, and deaths, as well as changes in other factors such as economic opportunities, real estate markets, and migration patterns.

\subsection{Social vulnerability}

11 | Accepted to Applied Geography on 12/19/2017. Published version: https://doi.org/10.1016/j.apgeog.2017.12.019 
There are myriad definitions, frameworks, and models for social vulnerability (Preston, Yuen, and Westaway 2011; see reviews McDowell, Ford, and Jones 2016; Wisner 2016). We take two approaches here, an individual indicator approach and an aggregate-based index approach. For the former, we quantify the number of people in vulnerable sub-populations who are at risk to inundation exposure including racial and ethnic minorities, elderly, women, people in poverty, and people with low educational attainment. We assess absolute and relative change for these sub-populations' risk between 2010 and 2050. For the latter, we use a modified version of the Social Vulnerability Index (SoVI) applied by Emrich and Cutter (2011), but within the conceptual framework of Jurgilevich et al (2017) where:

$$
\text { Risk }=f(\text { Vulnerability, Hazard, Exposure })
$$

In this risk framework, vulnerability is always in the social domain and is driven by the socioeconomic conditions that affect a sub-population's potential for harm when physically exposed to an environmental hazard or, in the case of this study, the impacts associated with the gradual environmental change expected from inundation due to future sea-level rise.

We conducted a SoVI-based approach using US Census tracts $(n=121)$ in the six county region of coastal Georgia for the years 2010 and 2050, but with a few modifications. The SoVI model has undergone a series of updates since its first iteration including 42 variables, then 32 , and now the latest version applies 27 variables; these changes have been linked to available data limitations as well as shifts in theoretical understanding of the primary drivers of social vulnerability (Cutter and Morath 2014). Due to the challenges associated with projecting many of these variables, however, we were limited to only nine of the variables from the latest version in our analysis. Our modeled socio-demographic characteristics that indicate increased levels of social vulnerability include race (specifically Asian, Black, and a non-white/non-Hispanic 
category we defined as "All Other Races" collected in the 2010 US Census), ethnicity

(Hispanic/Latinx), age dependence ( $\geq 65$ or $<5$ ), sex (specifically women), living in poverty, and low education as less than a $12^{\text {th }}$ grade educational attainment level.

The process of implementing SoVI is explained in detail by Dunning and Durden (2011). First, the SoVI model requires that census variables are standardized with $z$-scores. Second, a Principal Components Analysis (PCA) is conducted on the variables' $z$-scores using varimax rotation and the Kaiser criterion for component selection (i.e., eigenvalues >1). Third, the components of the PCA are then interpreted, named, and given a cardinality in relation to their theoretically understood influence on social vulnerability. Fourth, all component scores are summed by the unit of analysis to determine a unit's score. Fifth, scores are then mapped as quantiles to show relative levels of social vulnerability for the study area. The SoVI model assumes a theoretical link of explanatory power exists between the variance in socio-economic indicators and relative social vulnerability of an area. Although this connection is theoretical and difficult to empirically measure across broad geographic regions, we selected the SoVI model for this study due to its popularity in governmental planning (Dunning and Durden 2011, 2013; see Cutter et al. 2013; Evans et al. 2014) and because it has been tested for robustness and replicability (Schmidtlein et al. 2008; Tate 2012, 2013; Cutter and Morath 2014).

We ranked social vulnerability of US Census tracts into a three-tiered classification system of limited, moderate, and elevated levels based on standard deviations of SoVI scores following a previous approach (Emrich and Cutter 2011). We classified social vulnerability of census tracts that scored less than half a standard deviation below the mean score as limited, those within half a standard deviation of the mean as moderate, and those with more than half a standard deviation above the mean score as elevated. We recognize the sensitivity of model 
results to variable selection (Jones and Andrey 2007), yet we contend that these variables capture many of the characteristics that are likely to affect Georgia's coastal population under rising seas and maintain that our results are usable in coastal adaptation planning and policies.

\subsection{Inundation modeling}

To model inundation exposure on dryland, we used continuous elevation data based on high resolution Light Detection and Ranging (LiDAR) point data (10 $\mathrm{cm} \mathrm{RMSE}$ vertical accuracy). We tidally-adjusted the elevation data to the local mean higher high water (MHHW) datum with data available from the National Oceanic and Atmospheric Administration (Strauss et al. 2012; NOAA OCM 2015). Following a similar approach to Strauss et al. (2014), we employed a conservative three-fold approach to create a land/ocean layer. First, the area had to be above the MHHW mark in the elevation data to be considered land. Second, we marked all areas indicated as marine habitat in the US National Wetlands Inventory as ocean. Third, to ensure hydrologic connectivity between low-lying areas that are often overlooked in such assessments due to buried culverts not captured in elevation data, we classified streams and canals from the USGS National Hydrography Dataset high-resolution data as "ocean." To ensure connectivity to the shoreline, we only included areas that are connected to the National Shoreline (NOAA OCM 2016).

\subsection{Risk to sea-level rise}

By mid-century, Strauss et al. (2014) estimate a range of $0.09-0.55 \mathrm{~m}$ of sea-level rise above the 2012 level for the Georgia coast, which is based on locally-adapted scenarios of the Third National Climate Assessment's intermediate low, intermediate high, and high scenarios (Parris et al. 2012). We followed Strauss et al.'s (2014) approach and modeled the same locallyadjusted, mean curves with the intermediate low (globally $0.5 \mathrm{~m}$ by 2100 ) and high (globally 2.0 
m by 2100) estimates — what we call slow and fast scenarios for simplicity — to assess sea-level rise inundation for the year 2050. As our moderate scenario, we applied a locally-adjusted estimate for future global mean sea-level rise that is based on a semi-empirical model of sealevel rise (Vermeer and Rahmstorf 2009) informed by comprehensively modeled greenhouse gas emissions' effect on global warming (Ward and Mahowald 2014) under the Intergovernmental Panel on Climate Change high emissions scenario (see Hardy and Nuse 2016). To rank relative exposure, we applied the same three-tier classification system as for the SoVI results, but to the percentage area inundated for each tract.

We assessed relative levels of inundation exposure, social vulnerability, and risk (as a function of exposure and vulnerability) for tracts in Georgia's six coastal counties at the year 2050 using the slow, moderate, and fast sea-level rise scenarios. We assumed the populations and sub-populations within each tract were evenly distributed. The proportion of the tract land exposed to inundation was used to determine the proportion of its total population affected. This meant multiplying the projected population density (assessed based on available land) by the area forecast to be inundated under each sea-level rise scenario as done in other studies (Hauer, Evans, and Mishra 2016). We only evaluated aggregate social vulnerability (SoVI) for our middle population scenario. We applied this same approach for our individual indicator risk assessment.

A note on terminology for our population assessment. We use "exposed" to indicate the total population that is projected to experience inundation impacts due to sea-level rise independent of vulnerability status. This is the approach of previous studies (Hauer, Evans, and Alexander 2015; Hauer, Evans, and Mishra 2016). We use "at risk" to refer to the proportion of population affected in tracts with both elevated social vulnerability and any exposure to 


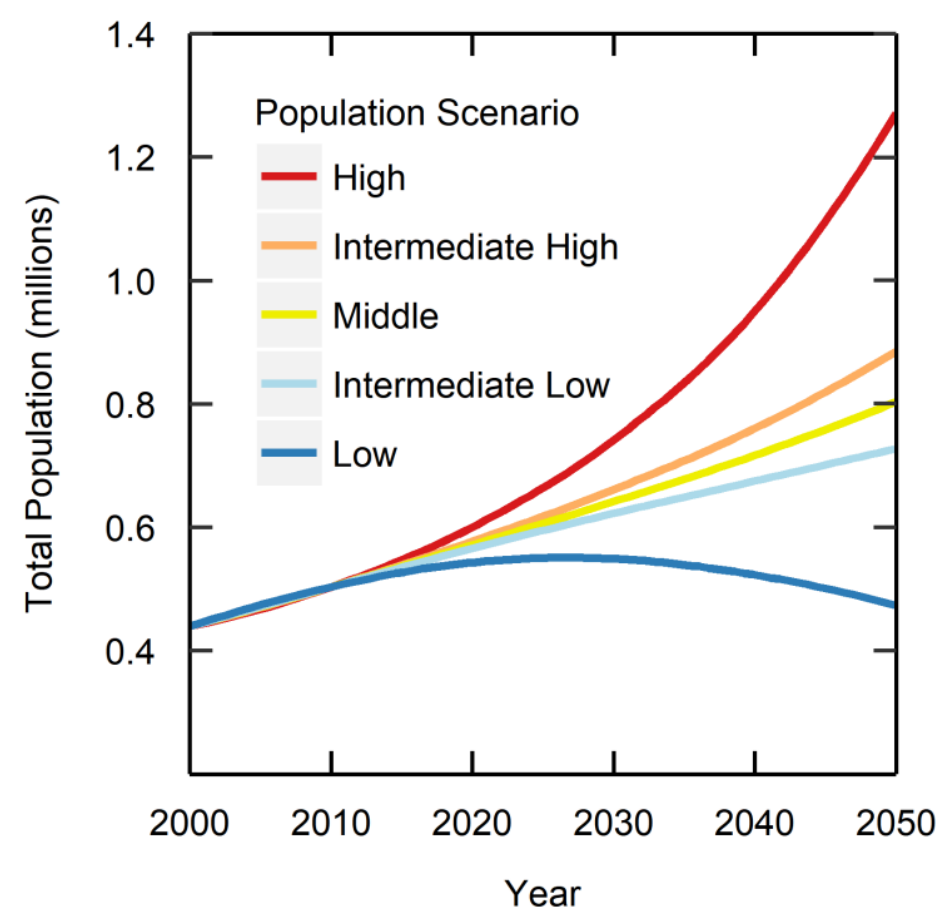

Figure 2. Population projection scenario totals for coastal Georgia's six counties. Data for 2000 and 2010 are from the US Census (see Section 2.2 for details). [one column]

inundation from rising seas. We apply "most at risk" to refer to the proportion of the population in tracts with elevated levels of both social vulnerability and inundation exposure following a three-tiered bivariate comparison similar to previously published research (Emrich and Cutter 2011). For the individual indicator risk assessment, we assess the proportion of each subpopulation that is exposed and define these populations as "at risk," although separately from the previous classifications.

\section{Results and discussion}

\subsection{Future population}

Our population scenarios project Georgia's coastal population to range from approximately 439,000 to 1.27 million with a middle projection of 803,000 by the year 2050 (Figure 2). [FOOTNOTE: Unless stated otherwise, all reported results in section 3 are for the middle scenario population projection.] Under all scenarios, this region becomes a majority non16 | Accepted to Applied Geography on 12/19/2017. Published version: https://doi.org/10.1016/j.apgeog.2017.12.019 


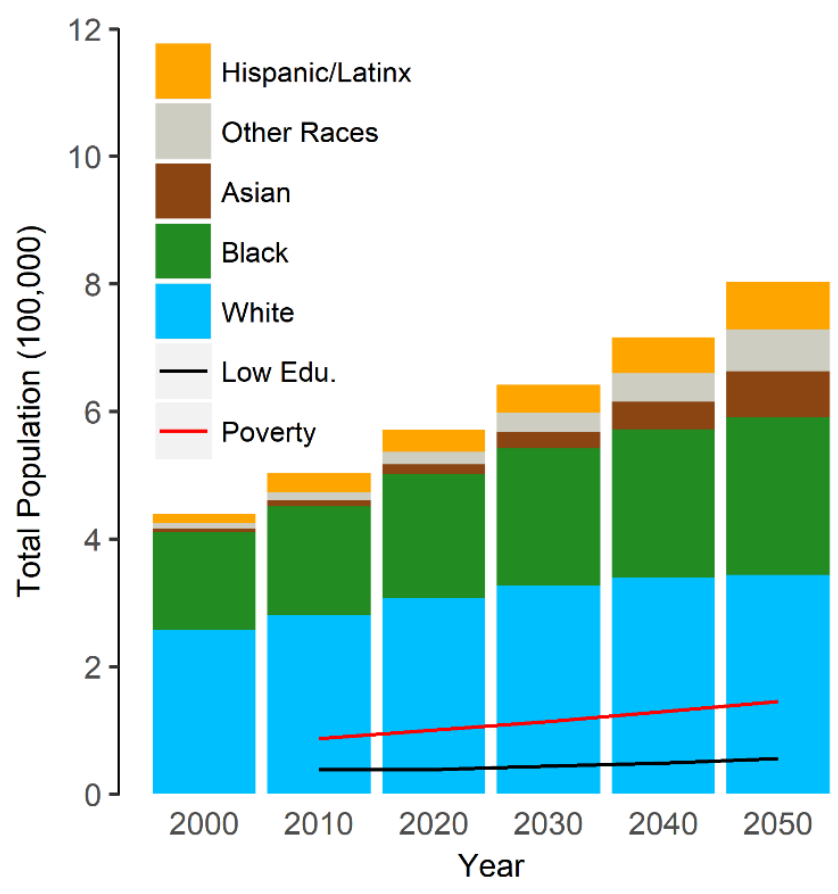

Figure 3. Sub-population projection (middle scenario) results for coastal Georgia's six counties. Data for 2000 and 2010 are from the US Census (see Section 2.2 for details). [one column]

white population by 2050 with slightly higher rates of poverty and lower rates of low educational attainment (Figure 3; see Figure S1 for percentages and Figures S2-S5 for results of other population projection scenarios). Compared with the U.S. Census's 2008-2012 American Community Survey estimates, the percentages of coastal Georgia's population aged 25 and above with low educational attainment declines over the projection period from $12.0 \%$ in 2010 to $10.3 \%$ in 2020 followed by a slow increase to $10.5 \%$ by 2050 . The total population with low education increases over this time from approximately 38,400 to 55,700 people, a $45 \%$ increase (Figure S1 \& S6). That the overall percentage of the population with low educational attainment decreases suggests this indicator should lead to declines in social vulnerability for coastal Georgia. In contrast, the total population living in poverty is projected to increase from $17.3 \%$ to $18.1 \%$, or from approximately 87,000 to 145,000 people; a $67 \%$ increase (Figure S1 \& S7). This is a relatively small increase in the total poverty rate; however, $0.8 \%$ of the projected population 


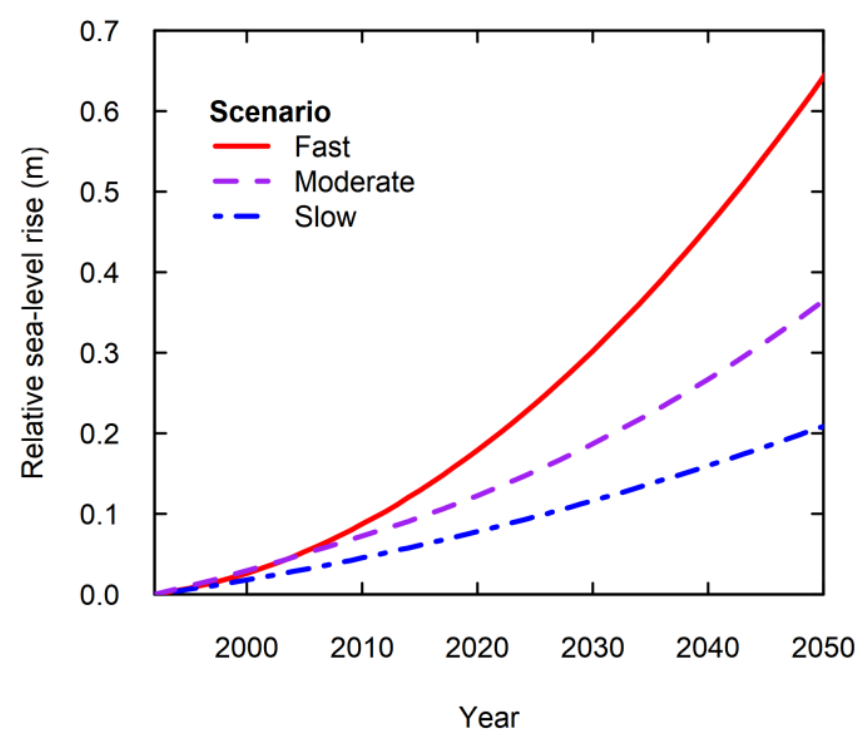

Figure 4. Locally adjusted mean sea-level rise projection scenarios for coastal Georgia, 1992-2050. See section 2.5 for details of each scenario. [one column]

equals nearly 6,400 more people in poverty than if the rate held constant. Thus, our model projects higher rates of social vulnerability due to an increased rate of those in poverty.

\subsection{Future inundation exposure, aggregate social vulnerability, and risk}

Our locally adjusted sea-level rise forecasts range from 0.21 to $0.64 \mathrm{~m}$ above the local 1992 sea level; the semi-empirically based moderate projection is $0.36 \mathrm{~m}$ (Figure 4). The area of land that would face loss due to inundation by the year 2050 under the three sea-level rise scenarios ranges from 82 to $285 \mathrm{~km}^{2}$, respectively. This would affect upland areas in 83 tracts for the slow and moderate scenarios and in 84 tracts for the fast scenario. Under the all three sealevel rise scenarios, we project a range of approximately 13,600 to 45,300 people that will be directly exposed to inundation due to sea-level rise by mid-century (Table 1). Of those that are exposed to inundation, approximately 5,000 to 14,900 people are projected to be at risk (i.e., residing in tracts with elevated levels of social vulnerability). This indicates that approximately $33 \%$ to $37 \%$ of the directly exposed population in 2050 are projected to reside in tracts with 
Table 1. Population exposed and the aggregate index assessment (via SoVI) for the at risk and most at risk populations. Assessments parsed by county (for 2050 projected population, middle scenario) and each sea-level rise scenario. At risk populations are the proportion of the exposed population in tracts with elevated social vulnerability. Most at risk populations are the proportion of the exposed population in tracts with elevated social vulnerability and elevated exposure.

\begin{tabular}{|c|c|c|c|c|c|c|c|c|}
\hline \multirow{2}{*}{$\begin{array}{l}\text { Sea-Level Rise } \\
\text { Scenario }\end{array}$} & \multirow[b]{2}{*}{ Bryan } & \multirow[b]{2}{*}{ Camden } & \multirow[b]{2}{*}{ Chatham } & \multirow[b]{2}{*}{ Glynn } & \multirow[b]{2}{*}{ Liberty } & \multirow[b]{2}{*}{ McIntosh } & \multicolumn{2}{|c|}{ TOTAL BY YEAR } \\
\hline & & & & & & & 2050 & 2010 \\
\hline \multicolumn{9}{|l|}{ Slow } \\
\hline \multicolumn{9}{|l|}{$0.21 \mathrm{~m}$ in 2050} \\
\hline Exposed & 703 & 1,657 & 5,819 & 2,853 & 223 & 2,316 & 13,571 & 7,649 \\
\hline At risk & 0 & 188 & 2,251 & 206 & 21 & 2,316 & 4,982 & 569 \\
\hline Most at risk & 0 & 66 & 0 & 0 & 20 & 2,246 & 2,332 & 25 \\
\hline \multicolumn{9}{|l|}{ Moderate } \\
\hline \multicolumn{9}{|l|}{$0.37 \mathrm{~m}$ in 2050} \\
\hline Exposed & 1,704 & 2,416 & 12,435 & 5,484 & 596 & 3,455 & 26,090 & 15,193 \\
\hline At risk & 0 & 392 & 4,624 & 756 & 59 & 3,455 & 9,286 & 1,132 \\
\hline Most at risk & 0 & 159 & 0 & 0 & 58 & 3,260 & $\mathbf{3 , 4 7 7}$ & 71 \\
\hline \multicolumn{9}{|l|}{ Fast } \\
\hline \multicolumn{9}{|l|}{$0.64 \mathrm{~m}$ in 2050} \\
\hline Exposed & 2,878 & 3,398 & 23,799 & 9,245 & 1,081 & 4,854 & 45,255 & 27,166 \\
\hline At risk & 0 & 717 & 7,957 & 1,263 & 126 & 4,854 & 14,917 & 2,007 \\
\hline Most at risk & 0 & 283 & 5,626 & 0 & 124 & 4,173 & 10,206 & 1,520 \\
\hline
\end{tabular}

relatively high social vulnerability and a limited capacity to cope with the stresses of inundation from sea-level rise. A few tracts $(n=8)$ are projected to have elevated levels of inundation exposure and social vulnerability with approximately 2,300 to 10,200 people identified to be the most at risk to sea-level rise in the year 2050 (Table 1; also see Figure 5 for map).

Comparing 2010 and 2050 estimates of population impacted, there is a $67 \%$ increase in the total population exposed to sea-level rise under the fast scenario from approximately 27,200 to 45,300 people, which is similar to previous estimates for coastal Georgia (Hauer, Evans, and Alexander 2015). 


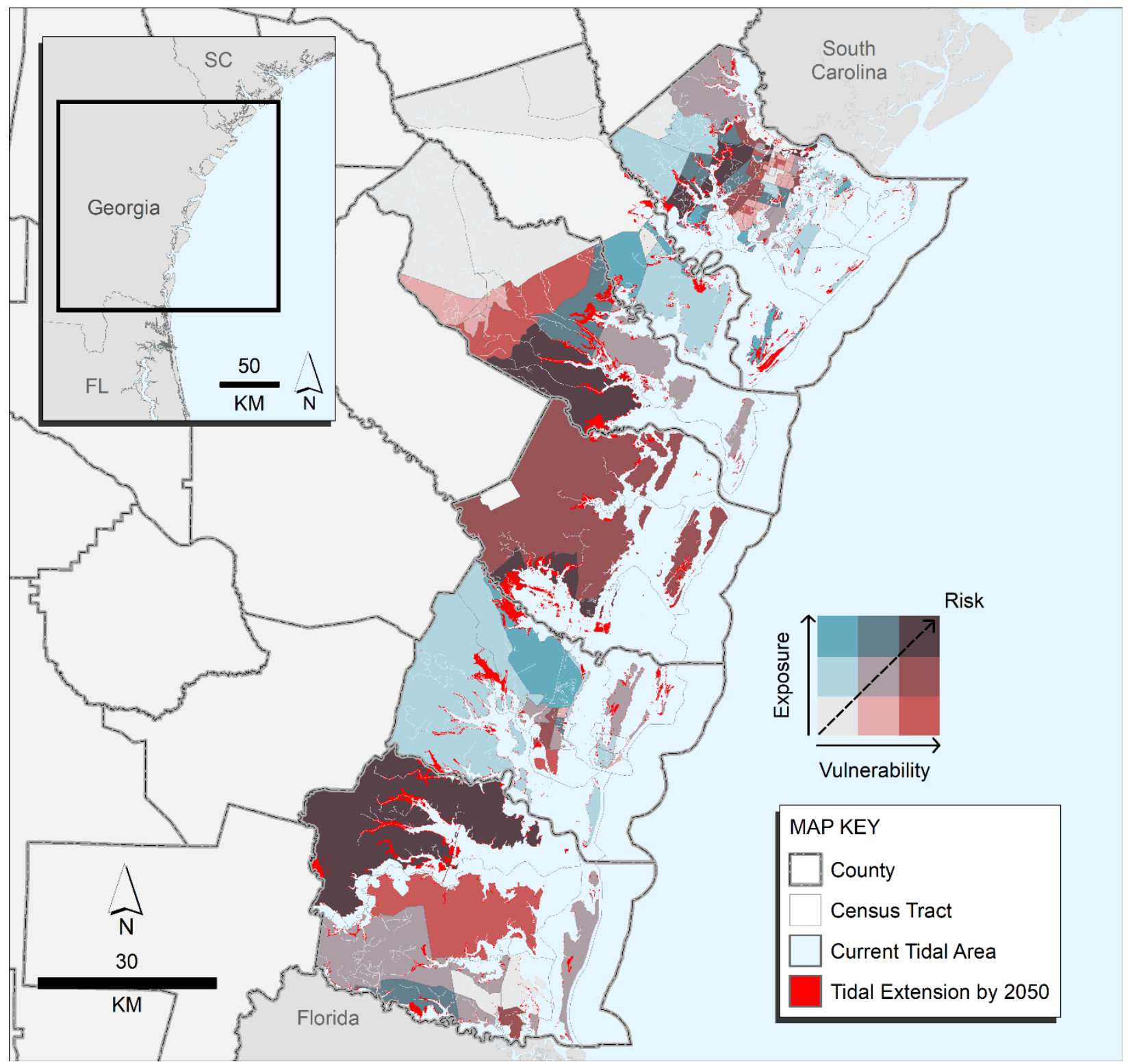

Figure 5. Coastal Georgia's risk to sea-level rise in the year 2050 under the fast sea-level rise scenario and middle population projection scenario. We used a bivariate plot to map the three-tiered classification schemes for both exposure to sea-level rise inundation (blue shades along y-axis) and social vulnerability (red shades along $\mathrm{x}$-axis). In the plot, relative level of risk increases in the "northeast" direction. The tracts colored dark brown have elevated levels of inundation exposure and social vulnerability. [two columns for Figures 5-8]

Critically, under the fast sea-level rise scenario our results indicate a much larger total at risk population in 2050 compared to results based on 2010 population data; the most at risk population is projected to substantially increase from about 1,500 to 10,200 over this period, a 
Table 2. SoVI results including principal components, variance explained, and dominant variable loadings for projected social vulnerability in the year 2050 .

\begin{tabular}{|c|c|c|c|c|c|}
\hline Component & $\begin{array}{l}\text { Score } \\
\text { Adjustment }\end{array}$ & $\begin{array}{l}\text { Component } \\
\text { Name }\end{array}$ & $\begin{array}{l}\text { Variance } \\
\text { Explained }\end{array}$ & $\begin{array}{l}\text { Dominant } \\
\text { Variables }\end{array}$ & $\begin{array}{r}\text { Component } \\
\text { Loading } \\
\end{array}$ \\
\hline \multirow{3}{*}{1} & \multirow{3}{*}{+} & \multirow{3}{*}{$\begin{array}{l}\text { Class/Race \& } \\
\text { Sex }\end{array}$} & \multirow{3}{*}{$38.0 \%$} & Poverty & 1.096 \\
\hline & & & & Women & 0.952 \\
\hline & & & & Black & 0.786 \\
\hline \multirow{2}{*}{2} & \multirow{2}{*}{$\|$} & Age \& & \multirow{2}{*}{$15.3 \%$} & Elderly/Youth & 0.787 \\
\hline & & Ethnicity & & Hispanic/Latinx & -0.689 \\
\hline
\end{tabular}

$580 \%$ increase (Table 1). We attribute the increase of the at risk and most at risk populations, at

least partially, to the relatively higher annual exponential growth rate in tract populations located along the shore with elevated levels of social vulnerability in 2050 (1.60\% mean annual growth, $n=21)$ compared to the growth in all shore adjacent tracts (1.26\% mean annual growth, $n=74)$. In other words, in shoreline tracts there are faster rates of population growth occurring in tracts with relatively higher social vulnerability.

The spatio-temporal changes in the socio-demographic characteristics driving aggregate social vulnerability are revealed by comparing the 2050 and 2010 SoVI results. Using our modified SoVI model, we identified 32 tracts with elevated social vulnerability in 2050 and 33 tracts in 2010 (Figure S8). We observed some overlap in the elevated tracts from 2010 and 2050 $(n=19)$. The characteristics explaining the elevated tracts stayed relatively consistent with a Class/Race (specifically Black) and Sex component loading as the most important indicators for the study region in both 2010 and 2050 followed by a Race/Ethnicity and Age component (Table 2 and Table S1). Rather than parsing the aggregate index further, we think it is more useful to evaluate the individual indicators of social vulnerability.

\subsection{Future projections of social vulnerability indicators}

Studies that previously applied SoVI or similar index-based approaches identified relative levels of vulnerability for the region of interest (e.g., Cutter, Boruff, and Shirley 2003; Emrich 

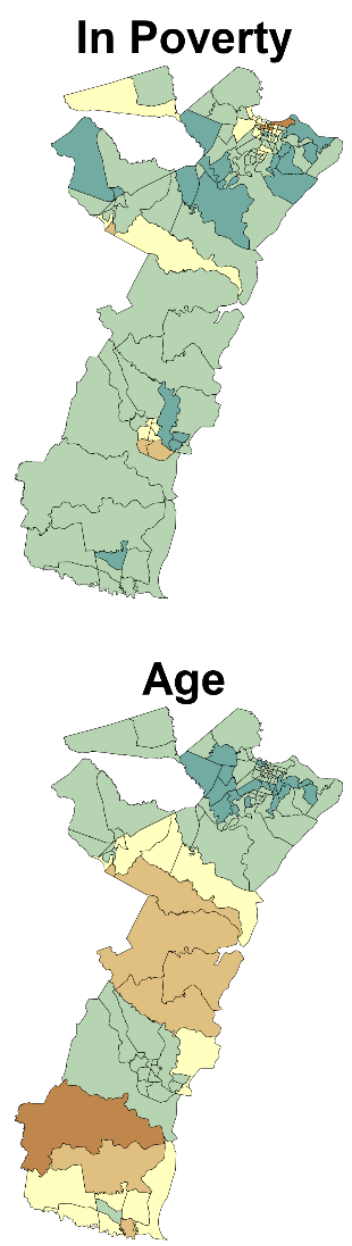
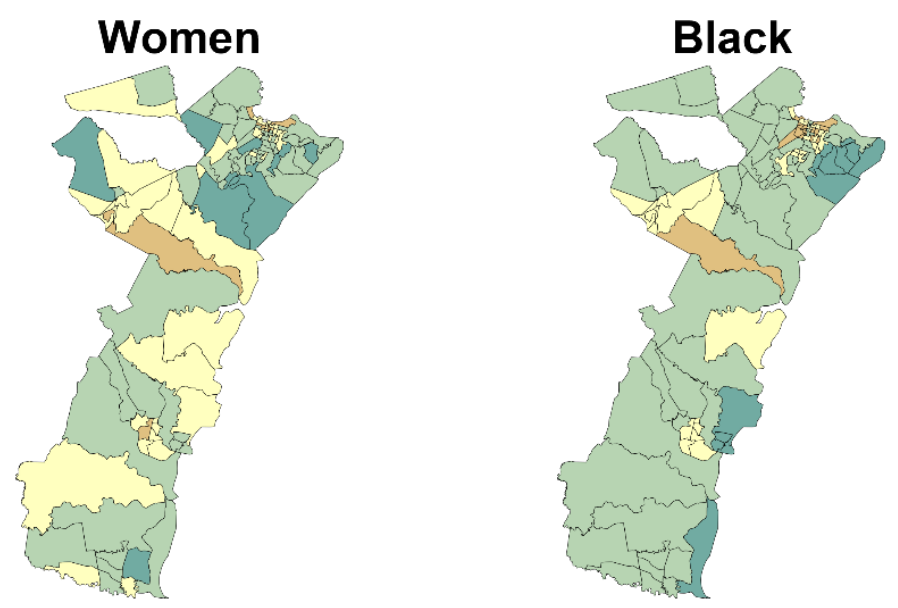

Figure 6. Year 2050 sub-populations. This map panel shows the relative importance over space for subpopulations typically associated with increased levels of social vulnerability. The map categories are based on standard deviations (SD) from the regional mean for each sub-population projection (middle scenario).

and Cutter 2011; Cutter et al. 2013; Frazier, Thompson, and Dezzani 2014; KC, Shepherd, and

Gaither 2015). Such assessments problematically assume, however, that the multi-dimensionality and heterogeneity of social vulnerability can be captured in a single aggregate index (Rufat 2013). While composite results are useful for broad scale hazard mitigation planning by identifying relative levels of social vulnerability for the study region, their usability is limited due to challenges associated with interpretability of the results (Lemos, Kirchhoff, and Ramprasad 2012). Aggregated results are challenging to apply in practice due to obscuring the reason why a certain area (e.g., a census tract) is identified as having a higher level of social 
vulnerability. While policy-makers may prefer an aggregated index, we contend that its usefulness for planning targeted mitigation of socially vulnerable sub-populations is limited (see Rufat 2013 for more discussion on this topic).

To improve interpretation of our aggregated SoVI results, we report the relative importance for each indicator used in our model (Figure 6). Whereas Table 2 suggests that the variable Black is important for explaining social vulnerability across the region, a map panel of relative importance of individual indicators allows identifying the spatial variability of the most important indicators by census tract. The map panel also shows that the explanation for the elevated levels of aggregate social vulnerability in tracts changes spatially between 2010 (Figure S9 and Table S1) and 2050. The reason that the tract in Liberty County scored highly in the aggregate index model in 2010 (indicated with an asterisk at its center in Figure S8a), for example, was primarily due to a combination of moderately elevated levels of women, people in poverty, and people with low educational attainment (Figure S9). In this tract, by 2050 age dependency becomes a more important factor while poverty becomes less important (Figure 6). Another example is in the Brunswick urban area, which shows two tracts with high social vulnerability in 2050 (Figure S4b) due to their relatively large Hispanic/Latinx populations and populations in poverty (Figure 6).

Without showing the map panel, the aggregate social vulnerability results (Figure S8b) would suggest that each tract with elevated social vulnerability across the region would need equally targeted mitigation for all of the characteristics in Table 2, which is not the case (see Figure 6). We contend that aggregate-based indices are more usable if the underlying spatial variability in indicators driving the regional vulnerability is shown to planners and others working to mitigate uneven social vulnerability at the local scale. The planning actions needed to 


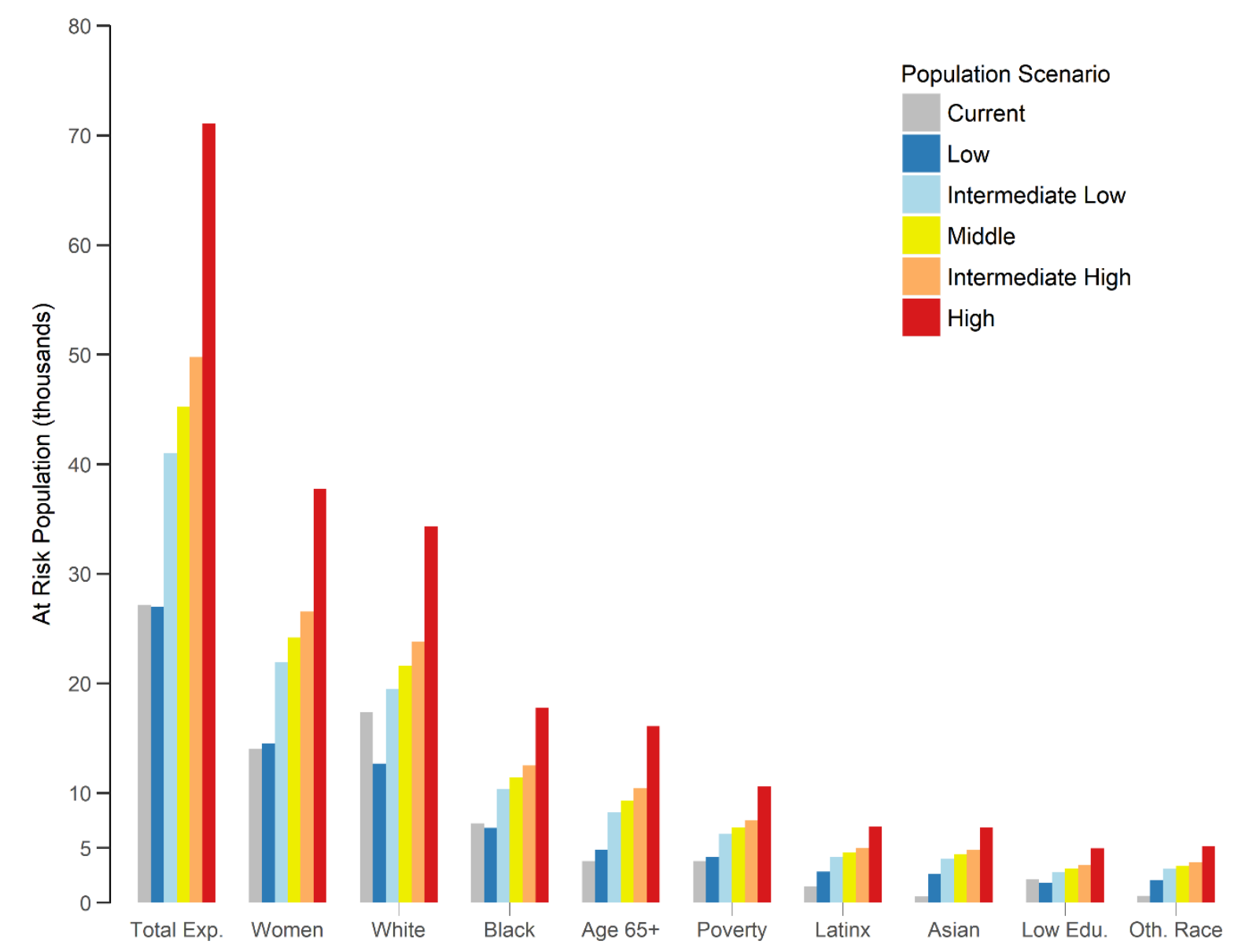

Figure 7. Absolute change in total and vulnerable sub-populations (including white sub-population) to inundation exposure under the fast sea-level rise scenario by 2050 .

mitigate vulnerability for an elderly sub-population, for example, will often not be the same set of actions needed for a population in poverty and/or with low education. We now take a step even further away from the aggregate approach and evaluate the at risk populations for each vulnerable sub-population.

Our results show an increase in the absolute number of people at risk for all subpopulations under all sea-level rise scenarios and all but the lowest population projection scenario (Figure 7; see Figures S10 \& S11 for projection estimates of at risk populations due to moderate and slow sea-level rise scenarios, respectively). As the largest sub-population assessed, women are unsurprisingly projected to have the largest increase in exposure. For example, for 


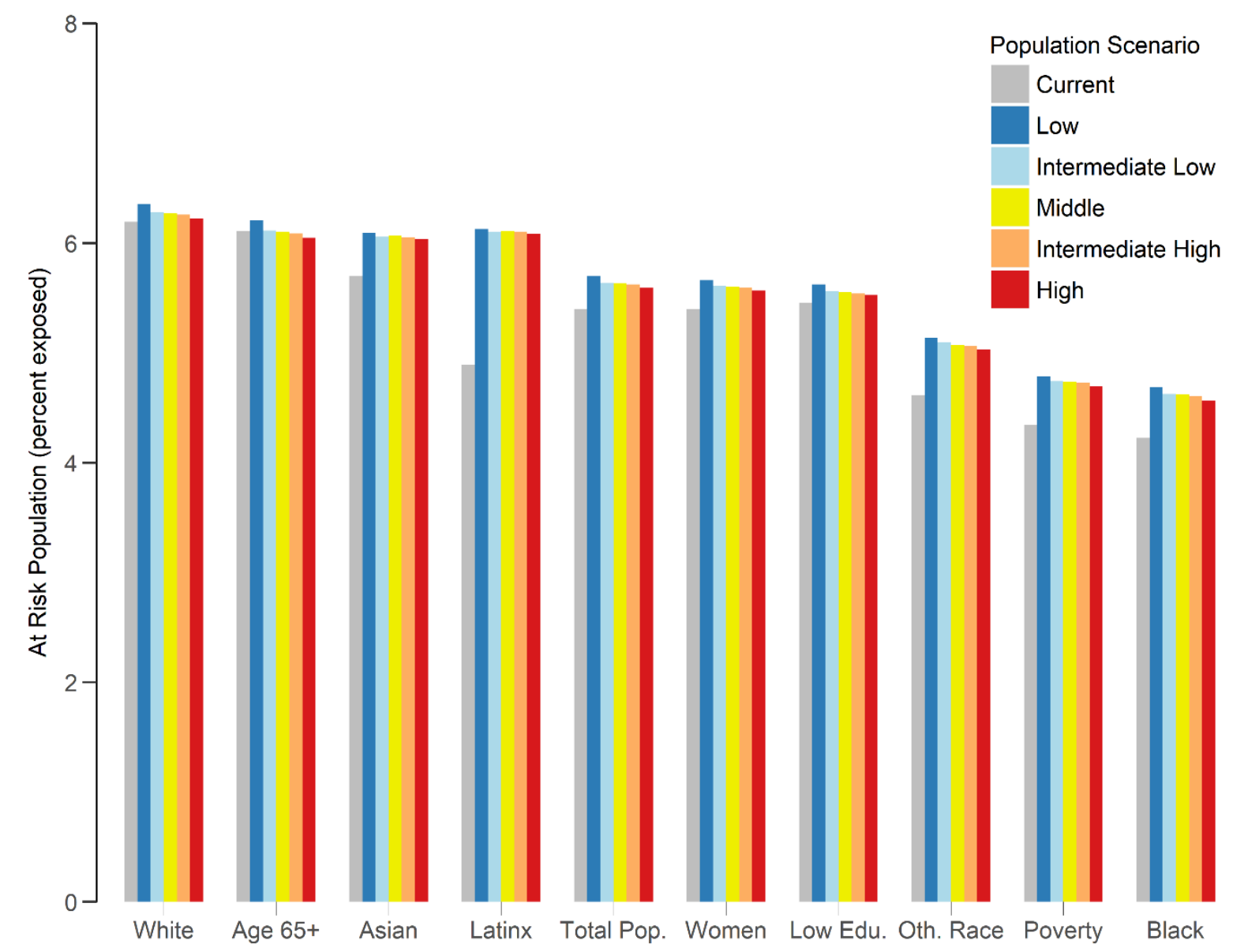

Figure 8. Percent change in total and vulnerable sub-populations at risk (including white sub-population) to inundation exposure under the fast sea-level rise scenario by 2050.

the middle population projection and fast sea-level rise scenario, women are projected to increase from approximately 14,000 to 24,000 exposed and the Hispanic/Latinx sub-population from approximately 1,500 to 4,600 between 2010 and 2050. Relatedly, the Hispanic/Latinx subpopulation had the largest percent increase from $4.9 \%$ to $6.1 \%$ between 2010 and 2050 (Figure 8). Otherwise, our results indicate that most sub-populations will have limited proportional increases (i.e., $\sim 0.5 \%$ or less) in their risk to inundation from sea-level rise under the fast scenario (see Figures S12 \& S13 for the moderate and slow sea-level rise scenarios).

Our findings suggest that while coastal Georgia will experience an absolute increase in the exposure of the total population and the risk for all vulnerable sub-populations under all sea- 
level rise scenarios, the region will see limited change in the relative proportion of each subpopulation at risk (except for the rapidly growing Hispanic/Latinx sub-population). One of the main messages from this key finding is relevant for interpreting previous and future studies quantifying social vulnerability of populations in coastal regions when using current population counts. For those coastal areas experiencing rapid growth (or declines) in more socially vulnerable sub-populations, estimates are likely to underestimate (or overestimate) the proportion of that group that will be impacted by inundation due to future sea-level rise. Based on the large historical growth for coastal populations in the United States (Crossett et al. 2013), and the estimated future population growth expected near the shoreline (Hauer, Evans, and Mishra 2016), we believe that future studies that estimate socially vulnerable populations in relation to sea-level rise should account for this phenomenon to improve their accuracy and relevance for long-term adaptation planning.

\subsection{Comparisons and limitations}

Based on our middle population projection scenario, our findings indicate that coastal Georgia's future population at risk to sea-level rise of $0.64 \mathrm{~m}$ by 2050 of 14,900 people is projected to be nearly triple one previous estimate of 5,000 based on 2010 population data (Strauss et al. 2014). We acknowledge that our inundation model did not explicitly take into account human-made barriers such as levees that the previous study included (Strauss et al. 2014). We believe, however, that inclusion of levees and seawalls would make a fractional improvement over the LiDAR-based elevation data. Further, we contend that these future populations would still be living below mean sea level, and as a result would be more at risk to the effects of sea-level rise including storm surge that may override the engineering solutions already in place (e.g., as with Hurricane Katrina; Leavitt and Kiefer 2006), or even innovative 
solutions of the future. Moreover, ours is a more conservative estimate, assessing the population below $0.64 \mathrm{~m}$ compared with the previous study's use of $0.9 \mathrm{~m}$. This explains why our 2010 estimate of 2,010 is lower than the previous study's estimate, at least partially.

Our findings match reasonably well with other studies for this region. For example, using a different methodology Hauer et al. (2015) reported similar magnitudes for the total population projected to be exposed to inundation due to sea-level rise by mid-century. Their projected mean estimates ranged from around 7,300 to 41,400 people compared to our middle scenario estimates of 13,600 to 45,300 (Table 1). The differences are likely related to our study using a different population projection method as well as different curves for sea-level rise. We applied locallyadjusted upper and lower bounds following the quadratic equation reported in Parris et al. (2012), which forecasts lower rates of rise by 2050 than the curves used by Hauer et al. (2015; see Clough, Park, and Fuller 2010). Hauer et al.'s (2015) higher curve would suggest that their estimate should be higher than our estimate. We used a different population projection methodology than Hauer et al. (2015) — the Hamilton-Perry method — which is known to have an upward bias for areas undergoing rapid population growth (Swanson, Schlottmann, and Schmidt 2010). That our estimates for the total population exposed are within a reasonably close range of Hauer et al.'s (2015) suggests that our approach aligns well with at least one independent projection for this region.

There are a few limitations to our approach worth acknowledging. First, we did not apply tract-specific limitations on growth, which would take into consideration "build-out" scenarios. We believe that our upper limits on global tract level growth controlled for this reasonably well. Under our highest population projection scenario, for example, the most densely populated tract (located in the city of Savannah) increased from approximately 3,000 to 8,000 people per square 
kilometer between 2010 and 2050. This is well within the feasible population density for an urban tract (Holt, Lo, and Hodler 2004). Second, we did not account for the possibility of technological innovations in coastal adaptation-including coastal emigration - that could lower the exposure of future populations, as this was beyond the scope of this project (more below). Racial and ethnic change are captured in our cohort change ratio, yet we held the structure of poverty constant (based on 2010) across time while the population changed and used constant enrollment rates for low education, which assumes stalled growth in educational attainment. Third, our model assumes that each specific sub-population's 2000 to 2010 CCR will stay steady over a 40-year window.

A fourth limitation is that our approach does not incorporate the effect of amenity migration or gentrification on a population's socio-economic structure (Hwang and Sampson 2014). CCRs implicitly account for both migration and mortality dynamics within a single age group's CCR. There still remains the possibility that sea-level rise will dramatically alter future migration patterns (Hauer 2017); however, our projections do not account for possible changes in migration patterns. We consider our use of various CCR scenarios as implicitly capturing these potential changes in total population migration patterns. It should be noted that migration data is rarely published at sub-county scales, potentially hampering future empirical migration scenarios at these scales. The use of CCRs for sub-county population projections are within acceptable projection approaches (see Baker et al. 2017). We do not account for all possible mechanisms that would lead to changes in specific group's CCRs (like economic opportunity, real estate market impacts, gentrification, etc.), but we do account for upper and lower bounds in our projection approach. Future studies that took more specific scenario building into consideration 
could more explicitly account for these dynamics and would be an improvement upon our approach.

Finally, we did not model a "full” spectrum of vulnerability indicators, as is typically done with the SoVI model using observed census data (Cutter and Morath 2014). We recognize that this limits our aggregate model's ability to capture the multi-dimensional nature of vulnerability as well as how different indicators have interactive effects that further exacerbate a group's vulnerability. For example, being an elderly white woman with low educational attainment would likely result in a greater vulnerability to sea-level rise than being elderly, but with a college degree and significant income or savings. Whereas the latter would have the capacity to move in the face of rising seas, the former would be limited in their ability to generate the resources needed to relocate. Moreover, we do not account for factors such as female head of household, as this would likely parse our data to the degree that nearly all of our CCRs would run towards zero and lead explosive growth rates by creating small denominators. We can imagine future work that takes our approach of temporally matching future populations with future environments and adds future economies to the creation of scenarios, much like the Shared Socioeconomic Pathways approaches recently developed for the Intergovernmental Panel on Climate Change (e.g., KC and Lutz 2017; Lutz and Muttarak 2017). How such scenarios are downscaled to sub-county geographies, however, remains a challenge for projecting the social vulnerability of future populations.

\section{Conclusion}

We applied a theory of socio-demographic change, demographic metabolism (Lutz 2013), to project social vulnerability and improve a sea-level rise risk assessment of coastal Georgia. We projected coastal Georgia's population to become majority non-white with higher 
rates of poverty and lower rates of low educational attainment by the year 2050. Our findings show that estimating the impacts on current socially vulnerable populations, as either aggregate indices or vulnerable sub-populations, leads to underestimating the absolute magnitude (and in many cases the proportion) of socially vulnerable populations of the future that will experience inundation from future sea-level rise under all the but the lowest population scenario. Importantly, our findings demonstrate how studies that assess social vulnerability based on current population counts are likely underestimating not only the absolute magnitude of subpopulations at risk, but also the proportional risk of sub-populations experiencing rapid growth in coastal regions.

Our temporal alignment of the social vulnerability of future populations with inundation exposure contributes knowledge toward "use-inspired research on vulnerability and adaptation" (Moser 2010, 467) with the goal of generating policy solutions for mitigating vulnerability to rising seas. We believe that our approach can empower local and state governments to develop more appropriately oriented vulnerability mitigation plans, targeting those with low educational attainment in specific areas, for example, while specifying needs for those in poverty in others. We imagine that our methodological approach of projecting future socially vulnerable populations and their relative risk could improve upon previous investigations (e.g., see Frazier et al. 2010 for storm surge; see Grineski et al. 2012 for heatwaves) in future climate-related hazard and climate justice studies.

Despite the limitations, we believe the approach we have presented answers a pressing need for more climate models that integrate climate change scenarios with scenarios of future social heterogeneity by accounting for poverty and other factors driving social inequality (Rao et al. 2017). Moreover, we believe that our approach for doing such integration at the sub-county 
scale - a more manageable scale for the city and county planners who will be coping with these

changes - is an innovation on the national and global scale integrated assessments that are the

current focus of integrated modeling.

\section{References}

Baker, J., D. A. Swanson, J. Tayman, and L. M. Tedrow. 2017. Cohort Change Ratios and their Applications. Cham, Switzerland: Springer Publishing International AG. https://dx.doi.org/10.1007/978-3-319-53745-0.

Bazuin, J. T., and J. C. Fraser. 2013. How the ACS gets it wrong: The story of the American Community Survey and a small, inner city neighborhood. Applied Geography 45:292-302. http://dx.doi.org/10.1016/j.apgeog.2013.08.013.

Bolin, B. 2007. Race, Class, Ethnicity, and Disaster Vulnerability. In Handbook of Disaster Research, 113-129.

Bolin, B., M. Jackson, and A. Crist. 1998. Gender Inequality, Vulnerability, and Disaster: Issues in Theory and Research. The Gendered Terrain of Disaster: Through Women's Eyes :2744.

Bullard, R. D. 1990. Dumping in Dixie: Race, Class, and Environmental Quality.

Clough, J. S., R. A. Park, and R. Fuller. 2010. SLAMM 6 beta Technical Documentation: Release 6.0.1 beta. Warren Pinnacle Consulting, Inc.

Colby, S. L., and J. M. Ortman. 2015. Projections of the size and composition of the U.S. population: 2014 to 2060. Washington D.C.: U.S. Census Bureau.

Crossett, K., B. Ache, P. Pacheco, and K. Haber. 2013. National Coastal Population Report: Population Trends from 1970 to 2020.

Culliton, T. J., M. A. Warren, Ti. R. Goodspeed, D. G. Remer, C. M. Blackwell, and J. J. McDonough III. 2010. 50 years of population change along the nation's coasts, 1960-2010.

Cutter, S. L., B. J. Boruff, and W. L. Shirley. 2003. Social vulnerability to environmental hazards. Social Science Quarterly 84 (2):242-261. http://dx.doi.org/10.1111/15406237.8402002.

Cutter, S. L., C. T. Emrich, D. P. Morath, and C. M. Dunning. 2013. Integrating social vulnerability into federal flood risk management planning. Journal of Flood Risk Management 6 (4):332-344. http://dx.doi.org/10.1111/jfr3.12018.

Cutter, S. L., and D. P. Morath. 2014. The evolution of the social vulnerability index. In Measuring vulnerability to natural hazards: Towards disaster resilient societies, ed. J. Birkmann, 304-321. New York: United Nations University Press

DeConto, R. M., and D. Pollard. 2016. Contribution of Antarctica to past and future sea-level rise. Nature 531 (7596):591-597. http://dx.doi.org/10.1038/nature17145.

Dunning, C. M., and S. Durden. 2011. Social vulnerability analysis methods for Corps planning. Institute for Water Resources: Army Corps of Engineers.

- 2013. Social Vulnerability Analysis: A Comparison of Tools. Institute for Water Resources: U.S. Army Corp of Engineers.

Emrich, C. T., and S. L. Cutter. 2011. Social Vulnerability to Climate-Sensitive Hazards in the Southern United States. Weather, Climate \& Society 3 (3):193-208. http:/dx.doi.org/10.1175/2011wcas1092.1. 
Evans, J., J. S. Pippin, D. Hardy, and M. E. Hauer. 2014. Social vulnerability and local hazard mitigation planning: Application and evaluation of a "SoVI-Lite" approach for Glynn County, Georgia. A report to the Georgia Department of Natural Resources. Athens, GA: University of Georgia. http://dx.doi.org/10.13140/2.1.2017.0566\%0A.

Frazier, T. G., C. M. Thompson, and R. J. Dezzani. 2014. A framework for the development of the SERV model: A Spatially Explicit Resilience-Vulnerability model. Applied Geography 51:158-172. http://dx.doi.org/10.1016/j.apgeog.2014.04.004.

Frazier, T. G., N. Wood, B. Yarnal, and D. H. Bauer. 2010. Influence of potential sea level rise on societal vulnerability to hurricane storm-surge hazards, Sarasota County, Florida. Applied Geography 30 (4):490-505. http://dx.doi.org/10.1016/j.apgeog.2010.05.005.

Gaillard, J. C., M. Glantz, I. Kelman, B. Wisner, Z. Delica-Willison, and M. Keim. 2014. Back to the future - Taking the "naturalness" out of "natural" disaster (again): What about climate change? Natural Hazards Observer 38 (3):14-16.

Grineski, S. E., T. W. Collins, P. Ford, R. Fitzgerald, R. Aldouri, G. Velázquez-Angulo, M. de Lourdes Romo Aguilar, and D. Lu. 2012. Climate change and environmental injustice in a bi-national context. Applied Geography 33:25-35. https://doi.org/10.1016/j.apgeog.2011.05.013.

Hamilton, C. H., and J. Perry. 1962. A short method for projecting population by age from one decennial census to another. Social Forces 41 (2):163-170.

Hardy, R. D., and B. L. Nuse. 2016. Global sea-level rise: Weighing country responsibility and risk. Climatic Change 137 (3-4):333-345. http://dx.doi.org/10.1007/s10584-016-1703-4.

Hauer, M. E. 2017. Migration induced by sea-level rise could reshape the US population landscape. Nature Climate Change 7 (May):321-325. http://dx.doi.org/10.1038/NCLIMATE3271.

Hauer, M. E., J. Baker, and W. Brown. 2013. Indirect Estimates of Total Fertility Rate Using Child Woman/Ratio: A Comparison with the Bogue-Palmore Method. PLoS One 8 (6):e67226. http://dx.doi.org/10.1371\%2Fjournal.pone.0067226.

Hauer, M. E., J. M. Evans, and C. R. Alexander. 2015. Sea-level rise and sub-county population projections in coastal Georgia. Population and Environment :1-19. http://dx.doi.org/10.1007/s11111-015-0233-8.

Hauer, M. E., J. M. Evans, and D. R. Mishra. 2016. Millions projected to be at risk from sealevel rise in the continental United States. Nature Climate Change 6 (July):691-694. http://dx.doi.org/10.1038/nclimate2961.

Holt, J. B., C. P. Lo, and T. W. Hodler. 2004. Dasymetric Estimation of Population Density and Areal Interpolation of Census Data. Cartography and Geographic Information Science 31 (2):103-121. http://www.tandfonline.com/doi/abs/10.1559/1523040041649407.

Hwang, J., and R. J. Sampson. 2014. Divergent Pathways of Gentrification: Racial Inequality and the Social Order of Renewal in Chicago Neighborhoods. American Sociological Review 79 (4):726-751. http://dx.doi.org/10.1177/0003122414535774.

Jones, B., and J. Andrey. 2007. Vulnerability index construction: methodological choices and their influence on identifying vulnerable neighbourhoods. International Journal of Emergency Management 4 (2):269-295. https://doi.org/10.1504/IJEM.2007.013994.

Jurgilevich, A., A. Räsänen, F. Groundstroem, and S. Juhola. 2017. A systematic review of dynamics in climate risk and vulnerability assessments. Environmental Research Letters 12 (1):13002. http://dx.doi.org/10.1088/1748-9326/aa5508.

KC, B., J. M. Shepherd, and C. J. Gaither. 2015. Climate change vulnerability assessment in 
Georgia. Applied Geography 62:62-74. http://dx.doi.org/10.1016/j.apgeog.2015.04.007.

KC, S., and W. Lutz. 2014. Demographic scenarios by age, sex and education corresponding to the SSP narratives. Population and Environment 35 (3):243-260.

. 2017. The human core of the shared socioeconomic pathways: Population scenarios by age, sex and level of education for all countries to 2100. Global Environmental Change 42:181-192. https://doi.org/10.1016/j.gloenvcha.2014.06.004.

Kopp, R. E., R. M. DeConto, D. A. Bader, C. C. Hay, R. M. Horton, S. Kulp, M. Oppenheimer, D. Pollard, and B. H. Strauss. 2017. Evolving understanding of Antarctic ice-sheet physics and ambiguity in probabilistic sea-level projections. Earth's Future 5:1-17. http://arxiv.org/abs/1704.05597.

Kopp, R. E., R. M. Horton, C. M. Little, J. X. Mitrovica, M. Oppenheimer, D. J. Rasmussen, B. H. Strauss, and C. Tebaldi. 2014. Probabilistic 21st and 22nd century sea-level projections at a global network of tide-gauge sites. Earth's Future 2 (8):383-406. http://dx.doi.org/10.1002/2014EF000239.

Kulp, S., and B. H. Strauss. 2017. Rapid escalation of coastal flood exposure in US municipalities from sea level rise. Climatic Change. http://link.springer.com/10.1007/s10584-017-1963-7.

Leavitt, W. M., and J. J. Kiefer. 2006. Infrastructure interdependency and the creation of a normal disaster: The case of Hurricane Katrina and the City of New Orleans. Public Works Management \& Policy 10 (4):306-314. http://dx.doi.org/10.1177/1087724X06289055.

Lemos, M. C., C. J. Kirchhoff, and V. Ramprasad. 2012. Narrowing the climate information usability gap. Nature Climate Change 2 (11):789-794. http://dx.doi.org/10.1038/nclimate1614.

Logan, J. R., Z. Xu, and B. J. Stults. 2014. Interpolating U.S. Decennial Census Tract Data from as Early as 1970 to 2010: A Longitudinal Tract Database. The Professional Geographer 66 (3):412-420. http://dx.doi.org/10.1080/00330124.2014.905156.

Lutz, W. 2013. Demographic Metabolism: A Predictive Theory of Socioeconomic Change. Population and Development Review 38 (s1):283-301. http://dx.doi.org/10.1111/j.17284457.2013.00564.x.

Lutz, W., and S. KC. 2011. Global human capital: Integrating education and population. Science 333 (6042):587-593. http://dx.doi.org/10.1126/science.1206964.

Lutz, W., and R. Muttarak. 2017. Forecasting societies' adaptive capacities through a demographic metabolism model. Nature Climate Change 7 (3):177-184. http://www.nature.com/doifinder/10.1038/nclimate3222.

Martinich, J., J. Neumann, L. Ludwig, and L. Jantarasami. 2013. Risks of sea level rise to disadvantaged communities in the United States. Mitigation and Adaptation Strategies for Global Change :169-185. https://link.springer.com/article/10.1007/s11027-011-9356-0.

McDowell, G., J. Ford, and J. Jones. 2016. Community-level climate change vulnerability research: trends, progress, and future directions. Environmental Research Letters 11 (3):33001. http://stacks.iop.org/17489326/11/i=3/a=033001?key=crossref.9a7d639d25fcfcc4b858b70591561815.

Moser, S. C. 2010. Now more than ever: The need for more societally relevant research on vulnerability and adaptation to climate change. Applied Geography 30 (4):464-474. http://dx.doi.org/10.1016/j.apgeog.2009.09.003.

Neumann, B., A. T. Vafeidis, J. Zimmermann, and R. J. Nicholls. 2015. Future coastal population growth and exposure to sea-level rise and coastal flooding - A global 
assessment. PLoS One 10 (3):e0118571.

http://dx.doi.org/10.1371\%2Fjournal.pone.0118571.

Neumayer, E., and T. Plümper. 2007. The gendered nature of natural disasters: The impact of catastrophic events on the gender gap in life Expectancy, 1981-2002. Annals of the Association of American Geographers 97 (3):551-566. http://dx.doi.org10.1111/j.14678306.2007.00563.x.

Ngo, E. B. 2001. When Disasters and Age Collide: Reviewing Vulnerability of the Elderly. Natural Hazards Review 2 (2):80-89.

NOAA OCM. 2015. Inundation Mapping Tidal Surface - Mean Higher High Water. . 2016. National Oceanic and Atmospheric Administration Office of Coastal Management, Composite Shoreline.

http://shoreline.noaa.gov/data/datasheets/composite.html.

Otto, I. M., D. Reckien, C. P. O. Reyer, R. Marcus, V. Le Masson, L. Jones, A. Norton, and O. Serdeczny. 2017. Social vulnerability to climate change: A review of concepts and evidence. Regional Environmental Change :1-12. http:dx.doi.org/10.1007/s10113-0171105-9.

Parris, A., P. Bromirski, V. Burkett, D. D. Cayan, M. M. Culver, J. Hall, R. Horton, K. Knuuti, R. Moss, J. Obeysekera, A. Sallenger, and J. Weiss. 2012. Global Sea Level Rise Scenarios for the US National Climate Assessment. NOAA Tech Memo OAR CPO-1.

Preston, B. L., E. J. Yuen, and R. M. Westaway. 2011. Putting vulnerability to climate change on the map: A review of approaches, benefits, and risks. Sustainability Science 6 (2):177-202. http:dx.doi.org/10.1007/s11625-011-0129-1.

Rao, N. D., B. J. van Ruijven, V. Bosetti, and K. Riahi. 2017. Improving poverty and inequality modeling in climate research. Nature Climate Change 7 (December):857-862. http://dx.doi.org/10.1038/s41558-017-0004-x.

Rufat, S. 2013. Spectroscopy of Urban Vulnerability. Annals of the Association of American Geographers 103 (3):505-525. http://dx.doi.org/10.1080/00045608.2012.702485.

Rufat, S., E. Tate, C. G. Burton, and A. S. Maroof. 2015. Social vulnerability to floods: Review of case studies and implications for measurement. International Journal of Disaster Risk Reduction 14:470-486. http://dx.doi.org/10.1016/j.ijdrr.2015.09.013.

Schmidtlein, M. C., R. C. Deutsch, W. W. Piegorsch, and S. L. Cutter. 2008. A Sensitivity Analysis of the Social Vulnerability Index. Risk Analysis 28 (4):1099-1114. http://dx.doi.org/10.1111/j.1539-6924.2008.01072.x.

Shepherd, M., and B. KC. 2015. Climate Change and African Americans in the USA. Geography Compass 9 (11):579-591. http://dx.doi.org/10.1111/gec3.12244.

Smith, S. K., J. Tayman, and D. A. Swanson. 2001. State and Local Population Projections: Methodology and Analysis. New York, NY: Kluwer Academic/Plenum Publishers.

Spanger-Siegfried, E., K. Dahl, A. Caldas, S. Udvardy, R. Cleetus, P. Worth, and N. Hernandez Hammer. 2017. When Rising Seas Hit Home: Hard Choices Ahead for Hundreds of US Coastal Communities. Washington D.C. http://www.ucsusa.org/sites/default/files/attach/2017/07/when-rising-seas-hit-home-fullreport.pdf.

Spielman, S. E., D. Folch, and N. Nagle. 2014. Patterns and causes of uncertainty in the American Community Survey. Applied Geography 46:147-157.

http://dx.doi.org/10.1016/j.apgeog.2013.11.002.

Strauss, B. H., C. Tebaldi, S. Kulp, S. Cutter, C. Emrich, D. Rizza, and D. Yawitz. 2014. 
Georgia and the surging sea: A vulnerability assessment with projections for sea level rise and coastal flood risk. Climate Central Research Report.

Strauss, B. H., R. Ziemlinski, J. L. Weiss, and J. T. Overpeck. 2012. Tidally adjusted estimates of topographic vulnerability to sea level rise and flooding for the contiguous United States. Environmental Research Letters 7 (1). http://stacks.iop.org/1748-9326/7/i=1/a=014033.

Swanson, D. A., A. Schlottmann, and B. Schmidt. 2010. Forecasting the population of Census Tracts by age and sex: An example of the Hamilton-Perry Method in action. Population Research and Policy Review 29 (1):47-63. http://dx.doi.org/10.1007/s11113-009-9144-7.

Sweet, W. V, R. E. Kopp, C. P. Weaver, J. Obeysekera, R. M. Horton, E. R. Thieler, and C. E. Zervas. 2017. Global and Regional Sea Level Rise Scenarios for the United States. Silver Spring, MD.

Tamborini, C. R., C. H. Kim, and A. Sakamoto. 2015. Education and Lifetime Earnings in the United States. Demography 52 (4):1383-1407. http://dx.doi.org/10.1007/s13524-015-04070 .

Tate, E. 2012. Social vulnerability indices: a comparative assessment using uncertainty and sensitivity analysis. Natural Hazards 63 (2):325-347. http://dx.doi.org/10.1007/s11069012-0152-2.

. 2013. Uncertainty Analysis for a Social Vulnerability Index. Annals of the Association of American Geographers 103 (3):526-543. htp://dx.doi.org/10.1080/00045608.2012.700616.

US Census. 2012. American Community Survey 2012, 5-Year Estimate.

Vermeer, M., and S. Rahmstorf. 2009. Global sea level linked to global temperature. Proceedings of the National Academy of Sciences 106 (51):21527-21532.

Wailoo, K. 2010. Katrina's Imprint: Race and Vulnerability in America. Rutgers University Press.

Ward, D. S., and N. M. Mahowald. 2014. Contributions of developed and developing countries to global climate forcing and surface temperature change. Environmental Research Letters 9 (7):74008. http://stacks.iop.org/1748-9326/9/i=7/a=074008.

Wisner, B. 2016. Vulnerability as concept, model, metric, and tool. Oxford Research Encyclopedia of Natural Hazard Science :1-52. http://naturalhazardscience.oxfordre.com/view/10.1093/acrefore/9780199389407.001.0001/ acrefore-9780199389407-e-25.

Wisner, B., P. Blaikie, T. Cannon, and I. Davis. 2004. At Risk: Natural Hazards, People's Vulnerability and Disasters 2nd ed. Routledge. 


\section{Supplementary material}

\section{Social vulnerability projections improve sea-level rise risk assessments}

Table S1. SoVI results including principal components, variance explained, and dominant variable loadings for social vulnerability in the year 2010. Based on middle scenario population projection.

\begin{tabular}{|c|c|c|c|c|c|}
\hline Component & $\begin{array}{l}\text { Score } \\
\text { Adjustment }\end{array}$ & $\begin{array}{l}\text { Component } \\
\text { Name }\end{array}$ & $\begin{array}{l}\text { Variance } \\
\text { Explained }\end{array}$ & $\begin{array}{l}\text { Dominant } \\
\text { Variables }\end{array}$ & $\begin{array}{r}\text { Component } \\
\text { Loading }\end{array}$ \\
\hline \multirow{4}{*}{1} & \multirow{4}{*}{-} & \multirow{4}{*}{$\begin{array}{l}\text { Class/Race \& } \\
\text { Sex }\end{array}$} & \multirow{4}{*}{$38.6 \%$} & Poverty & -1.018 \\
\hline & & & & Black & -0.910 \\
\hline & & & & Low Education & -0.815 \\
\hline & & & & Women & -0.700 \\
\hline \multirow{3}{*}{2} & \multirow{3}{*}{$\|$} & \multirow{3}{*}{$\begin{array}{l}\text { Race/Ethnicity } \\
\text { \& Age }\end{array}$} & \multirow{3}{*}{$26.8 \%$} & Other Race & 1.037 \\
\hline & & & & Elderly/Youth & -0.695 \\
\hline & & & & Hispanic/Latinx & 0.521 \\
\hline
\end{tabular}




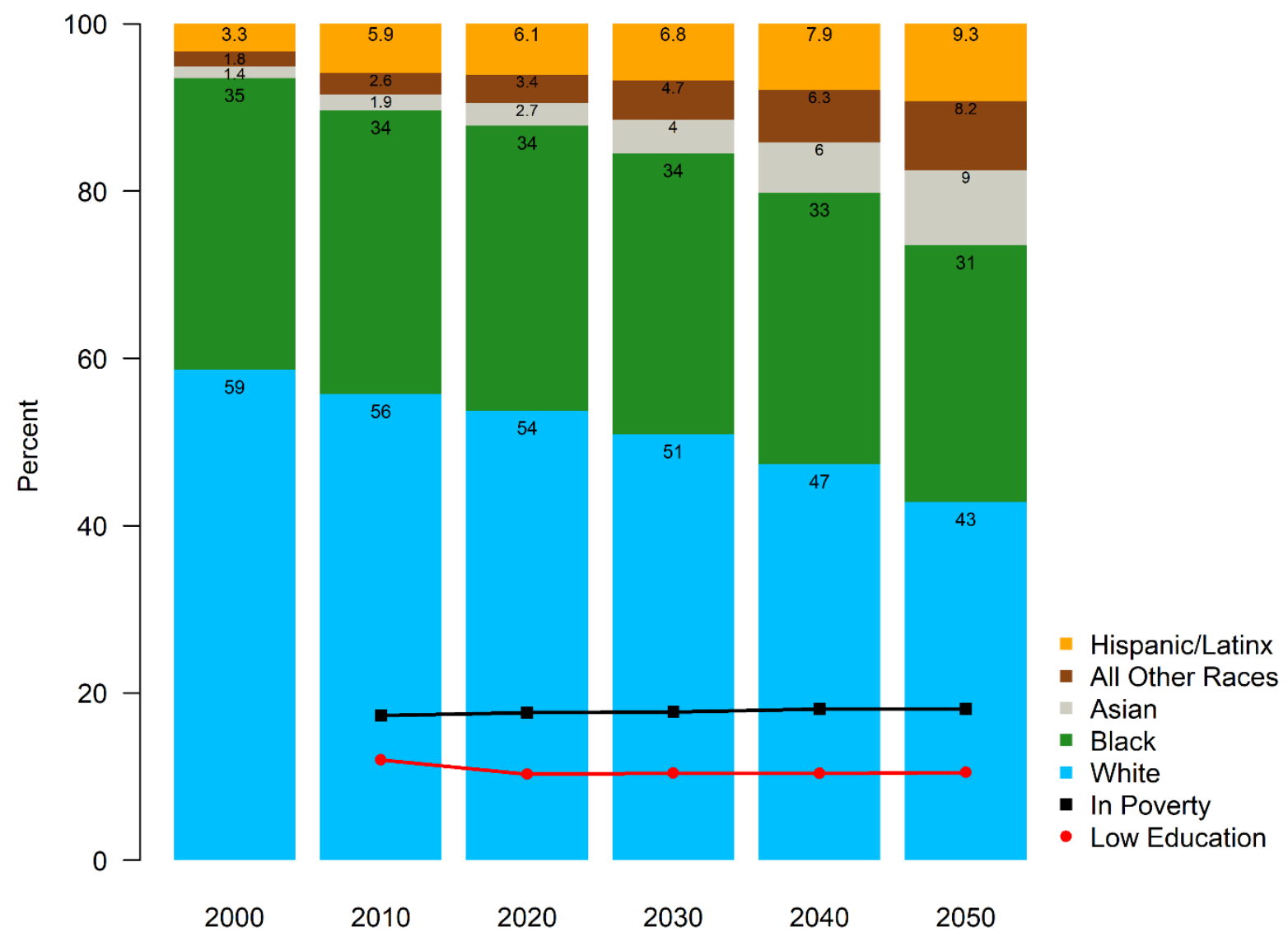

Figure S1. Population projection (middle scenario) for coastal Georgia's six counties as percentages. Data for 2000 and 2010 are from the US Census (see Section 2.2 for details). 


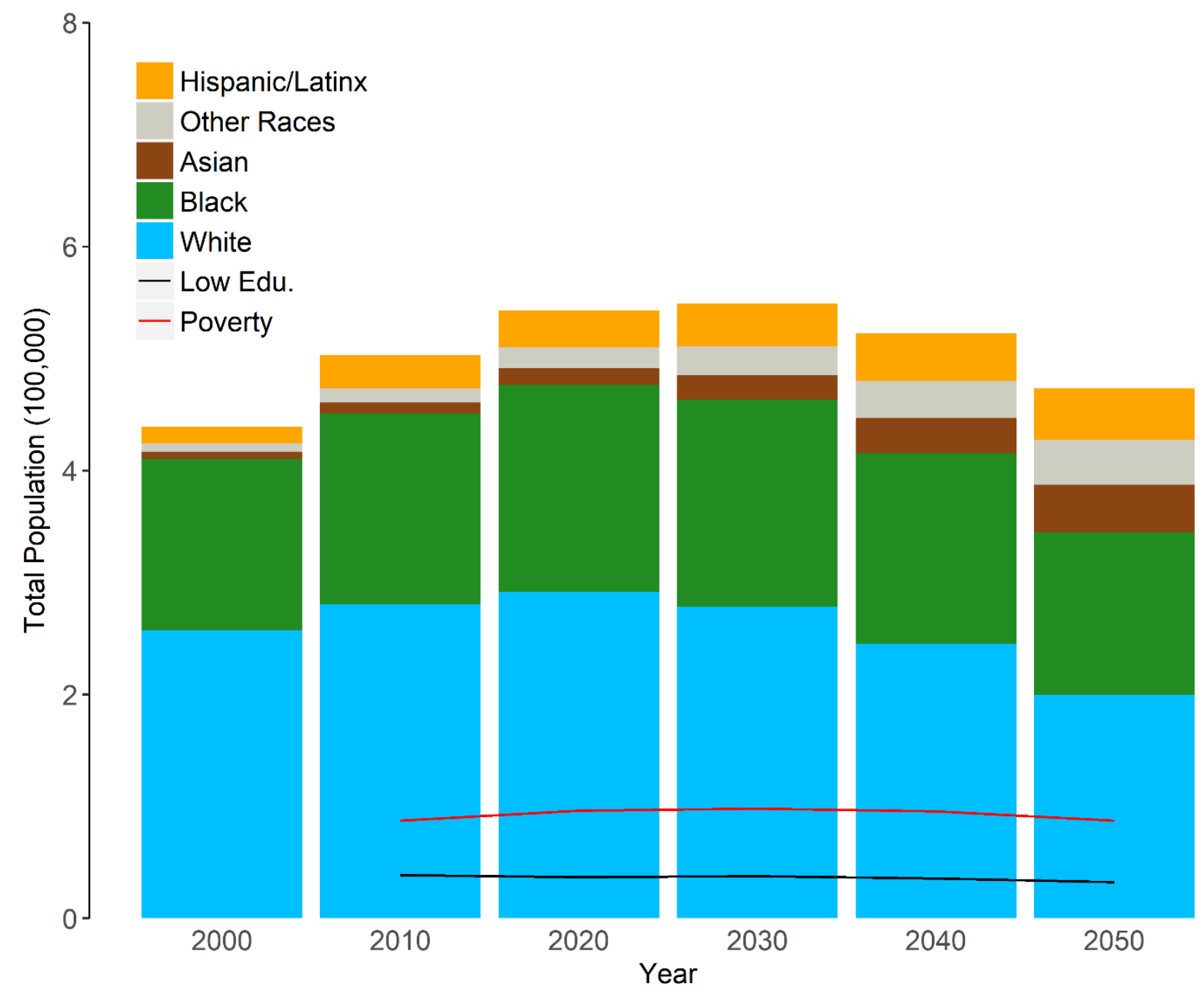

Figure S2. Population projection (low scenario) for coastal Georgia's six counties as percentages. Data for 2000 and 2010 are from the US Census (see Section 2.2 for details). 


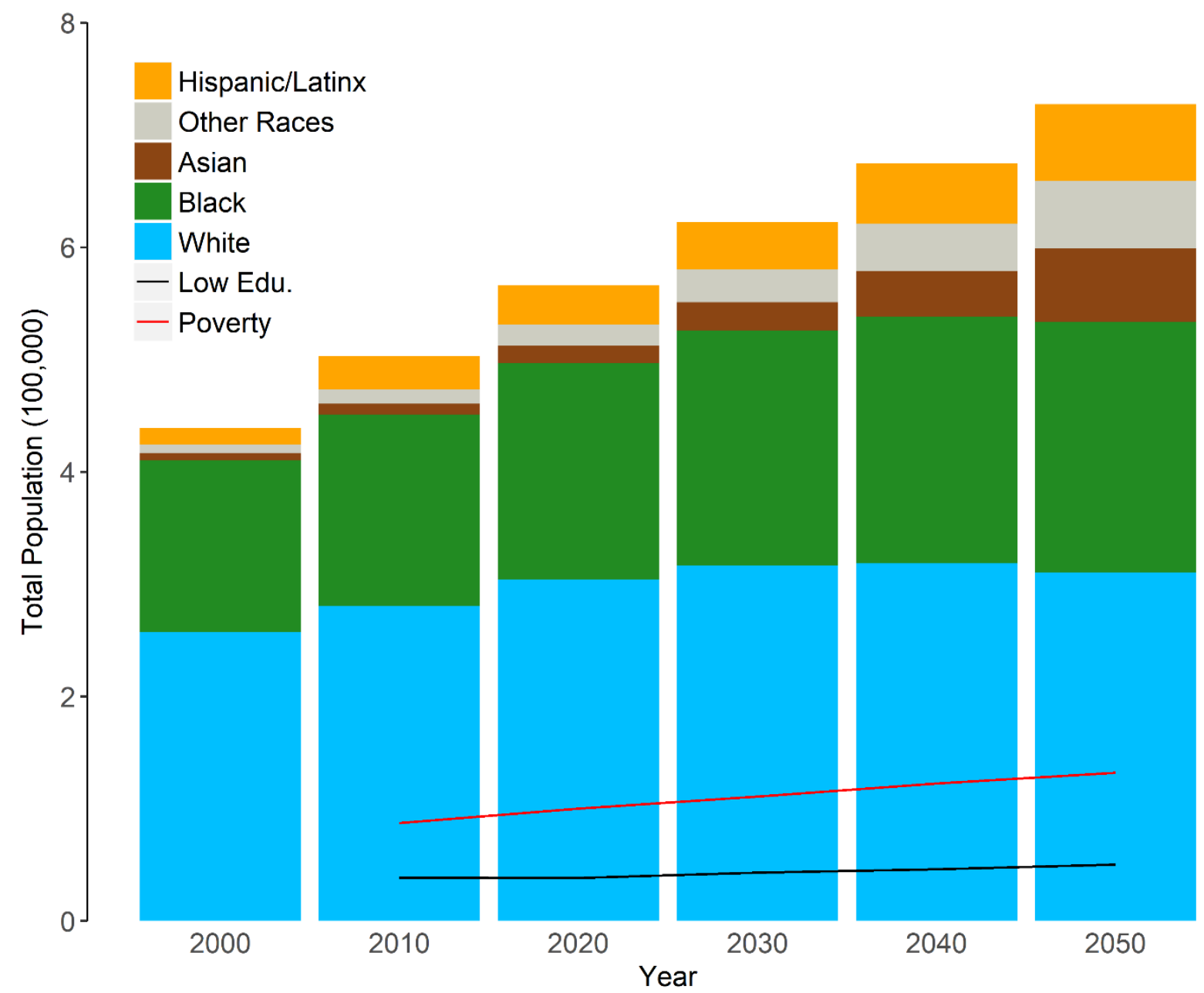

Figure S3. Population projection (intermediate low scenario) for coastal Georgia's six counties as percentages. Data for 2000 and 2010 are from the US Census (see Section 2.2 for details). 


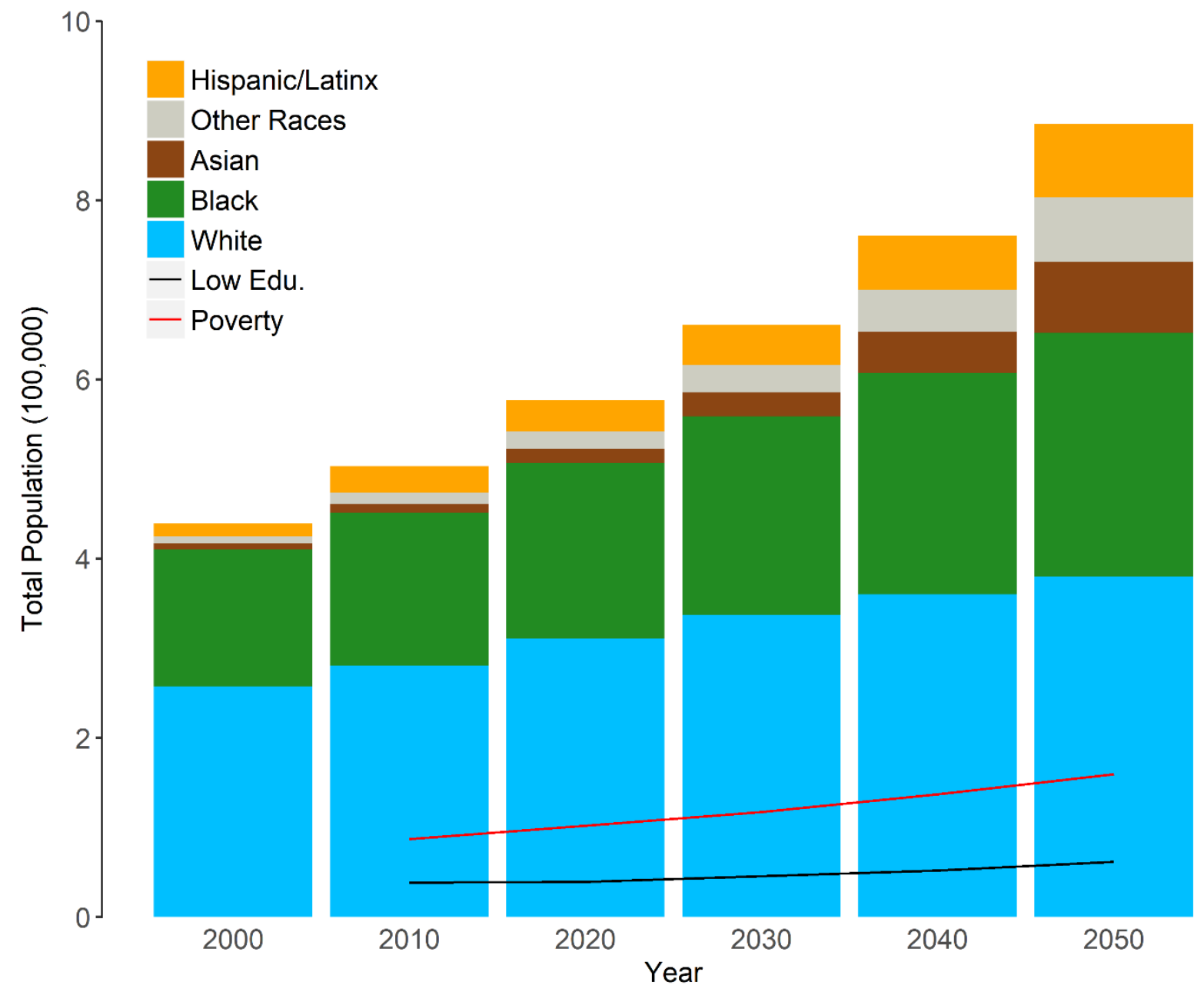

Figure S4. Population projection (intermediate high scenario) for coastal Georgia's six counties as percentages. Data for 2000 and 2010 are from the US Census (see Section 2.2 for details). 


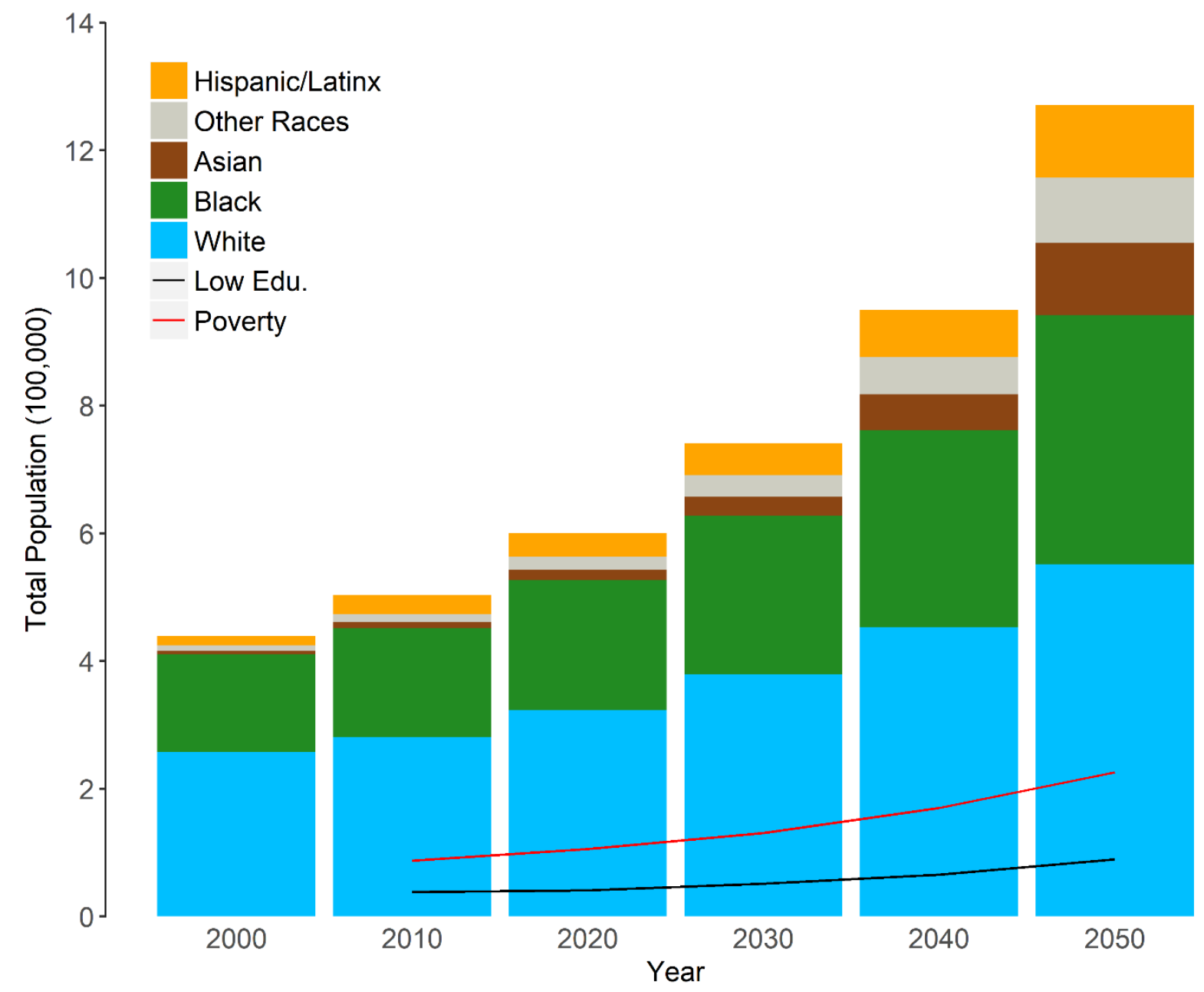

Figure S5. Population projection (high scenario) for coastal Georgia's six counties as percentages. Data for 2000 and 2010 are from the US Census (see Section 2.2 for details). 

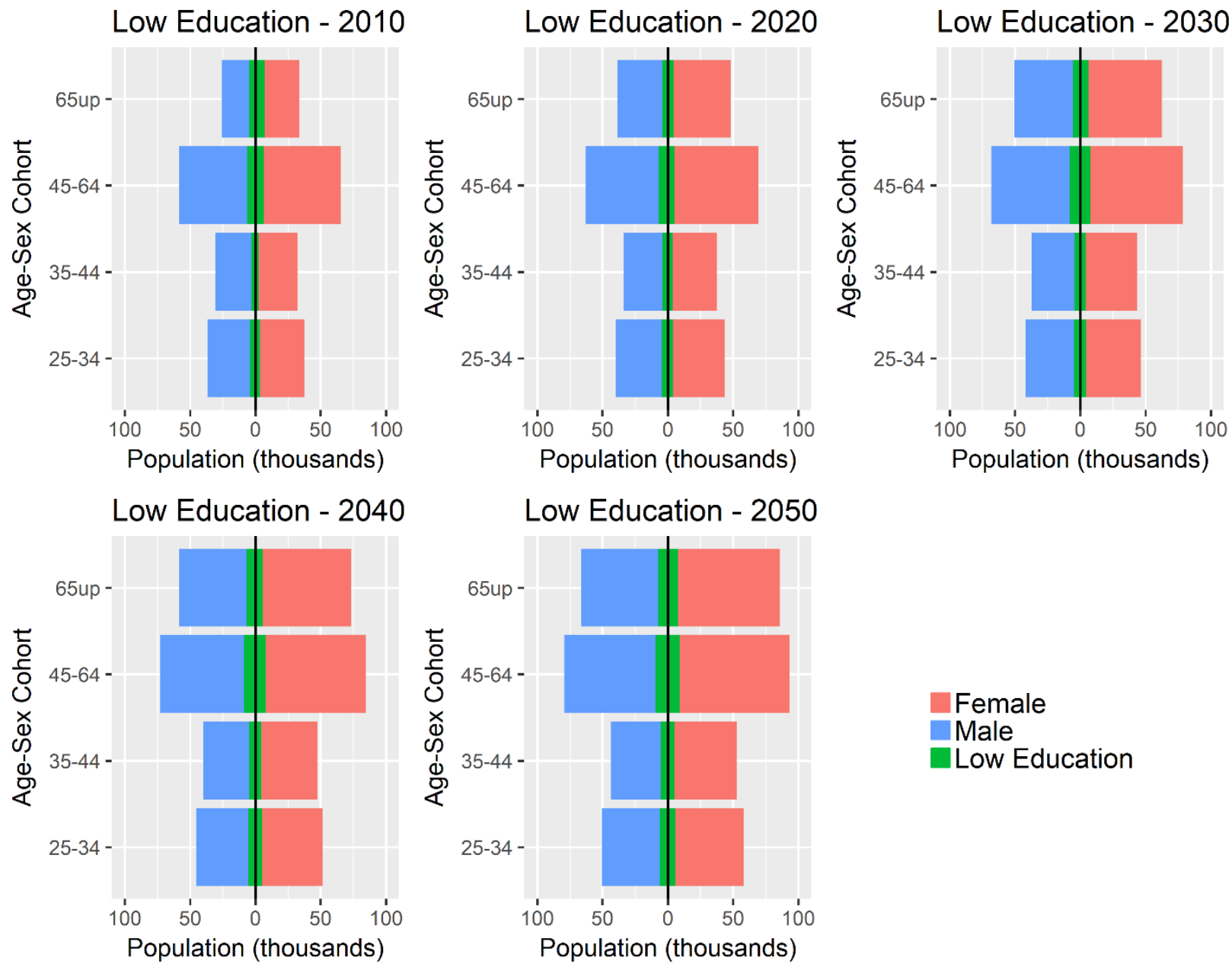

Figure S6. Population with low educational attainment. The "2010" time is from observed 20082012 ACS census data and 2020 to 2050 are from the middle population projection scenario. 

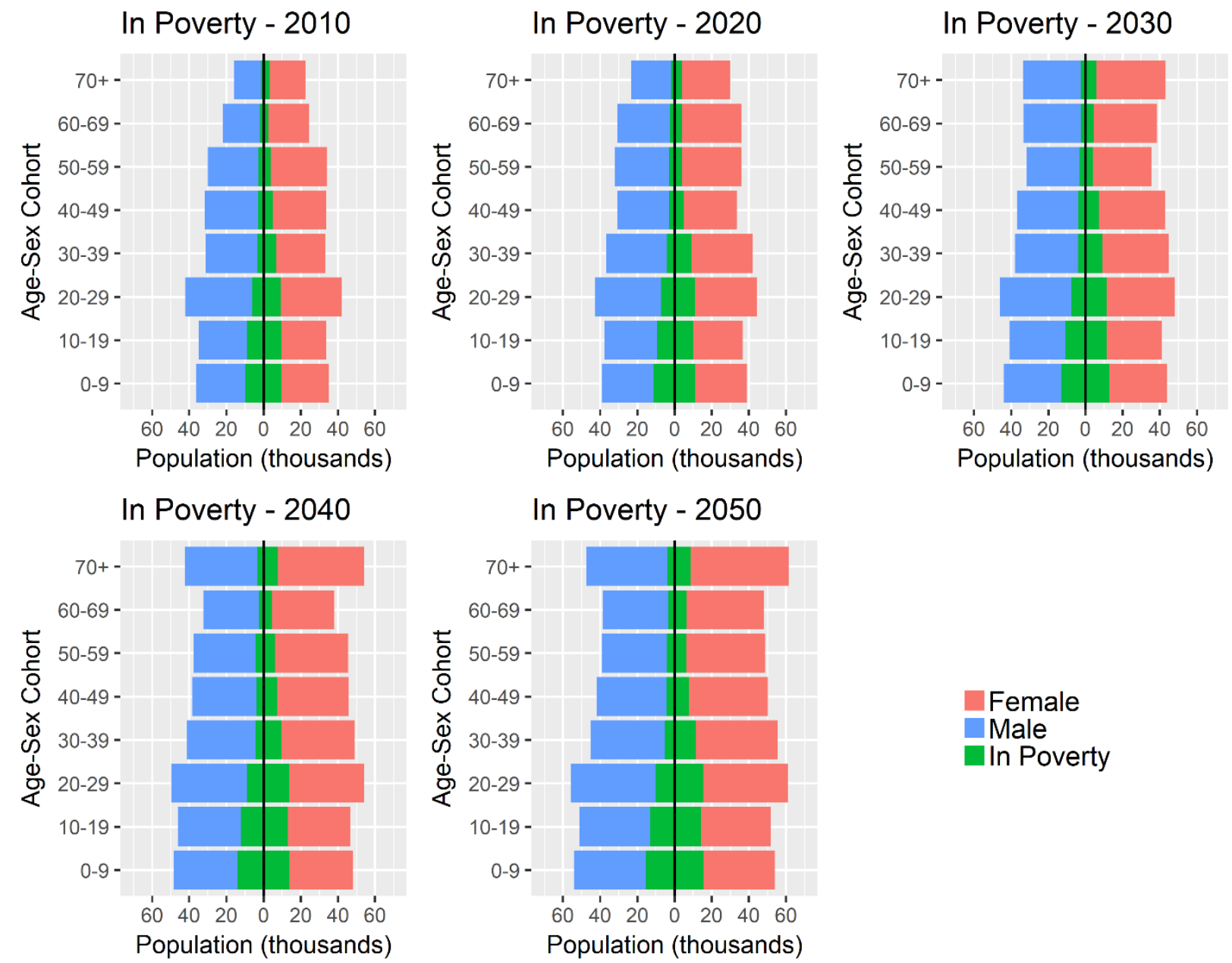

\section{Female \\ Male \\ In Poverty}

Figure S7. Population in poverty. The "2010" time is from observed 2008-2012 ACS census data and 2020 to 2050 are from the middle population projection scenario. 

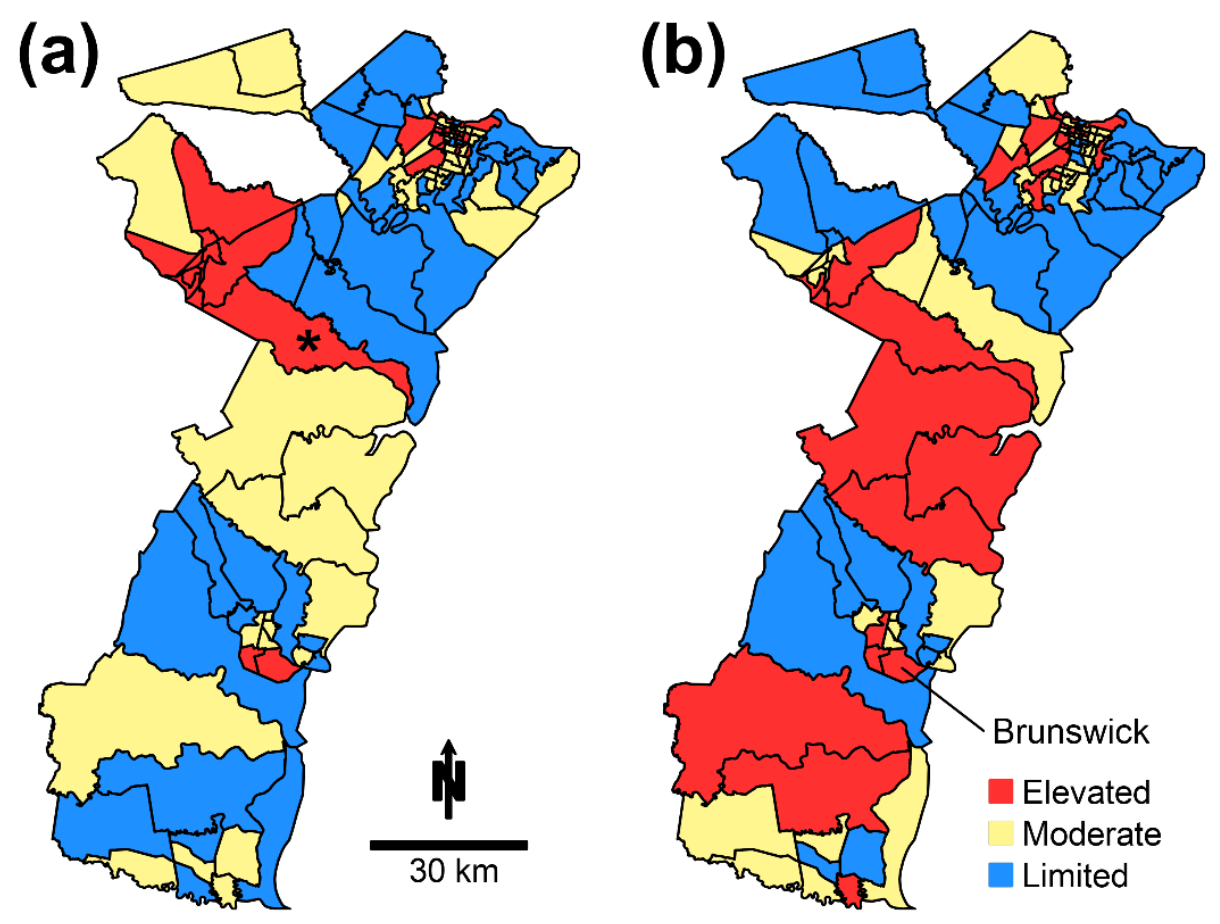

Figure S8. Year 2010 (a) and 2050 (b) social vulnerability aggregate index levels for census tracts on the Georgia coast. Map (b) is based on the middle population projection scenario. 

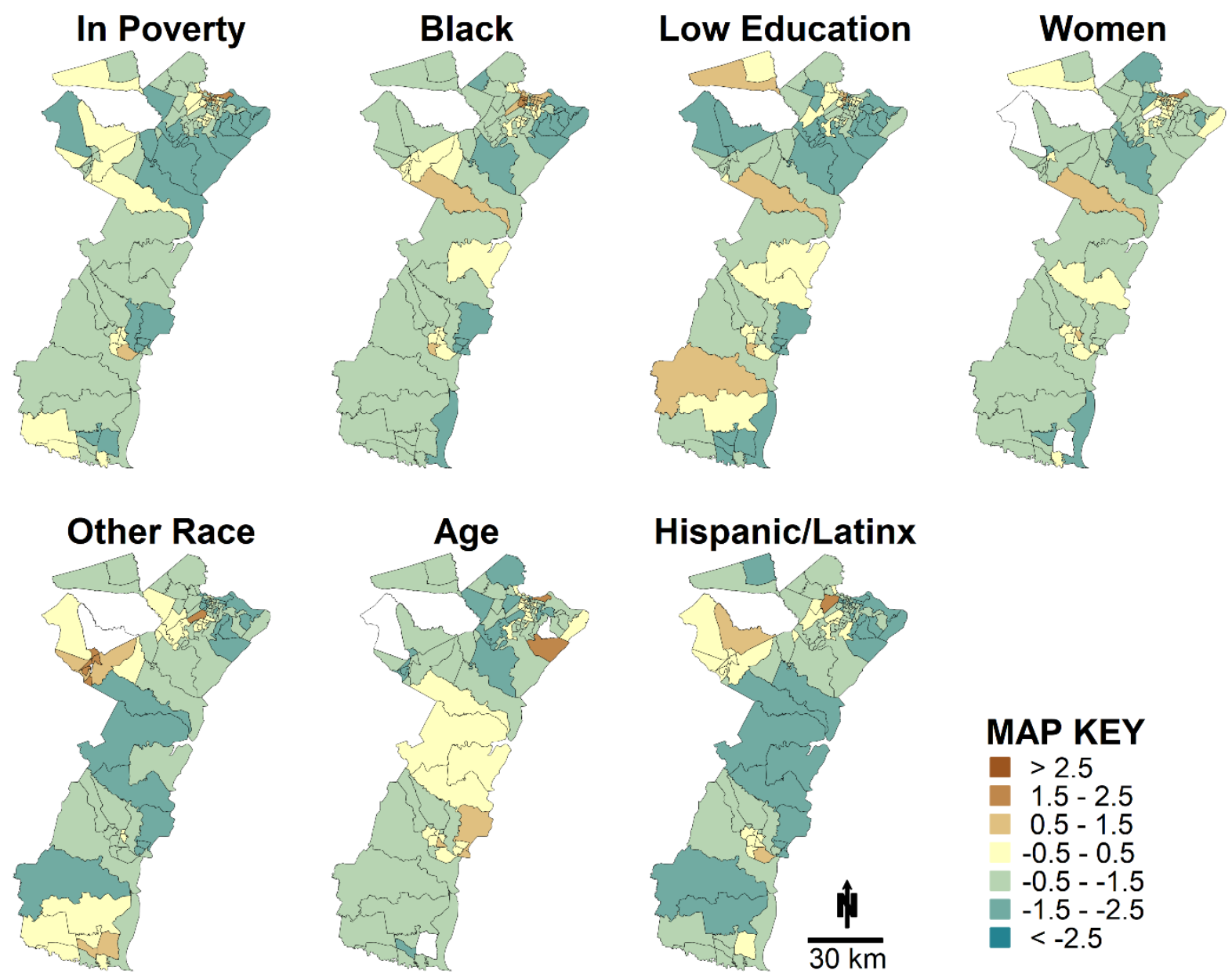

Figure S9. Map panel of indicators of most importance for 2010 SoVI. Map key categories are based on standard deviations (SD). Based on the middle population projection scenario. 


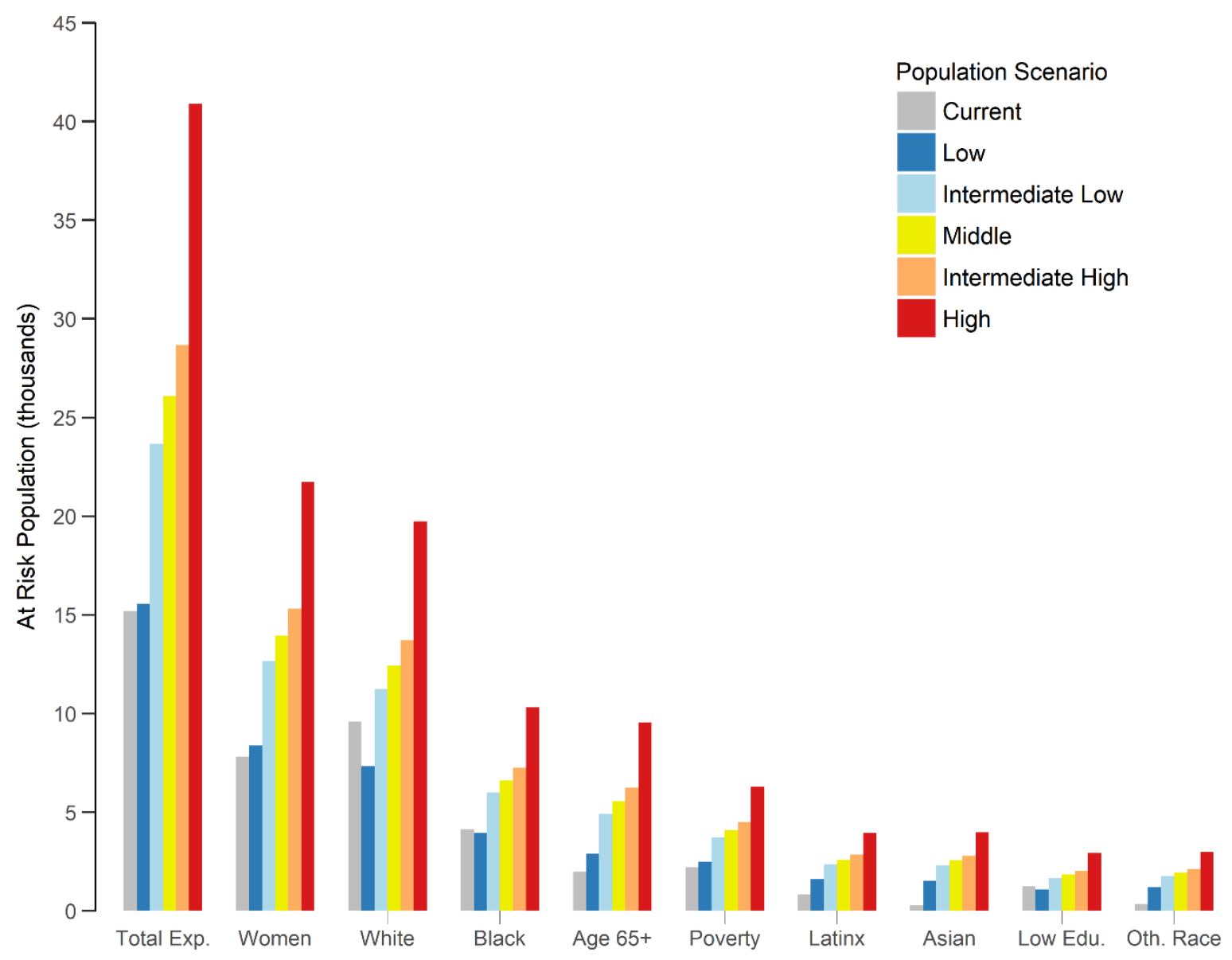

Figure S10. Absolute change in total and vulnerable sub-populations (including white subpopulation) to inundation exposure under the moderate scenario for sea-level rise by 2050 . 


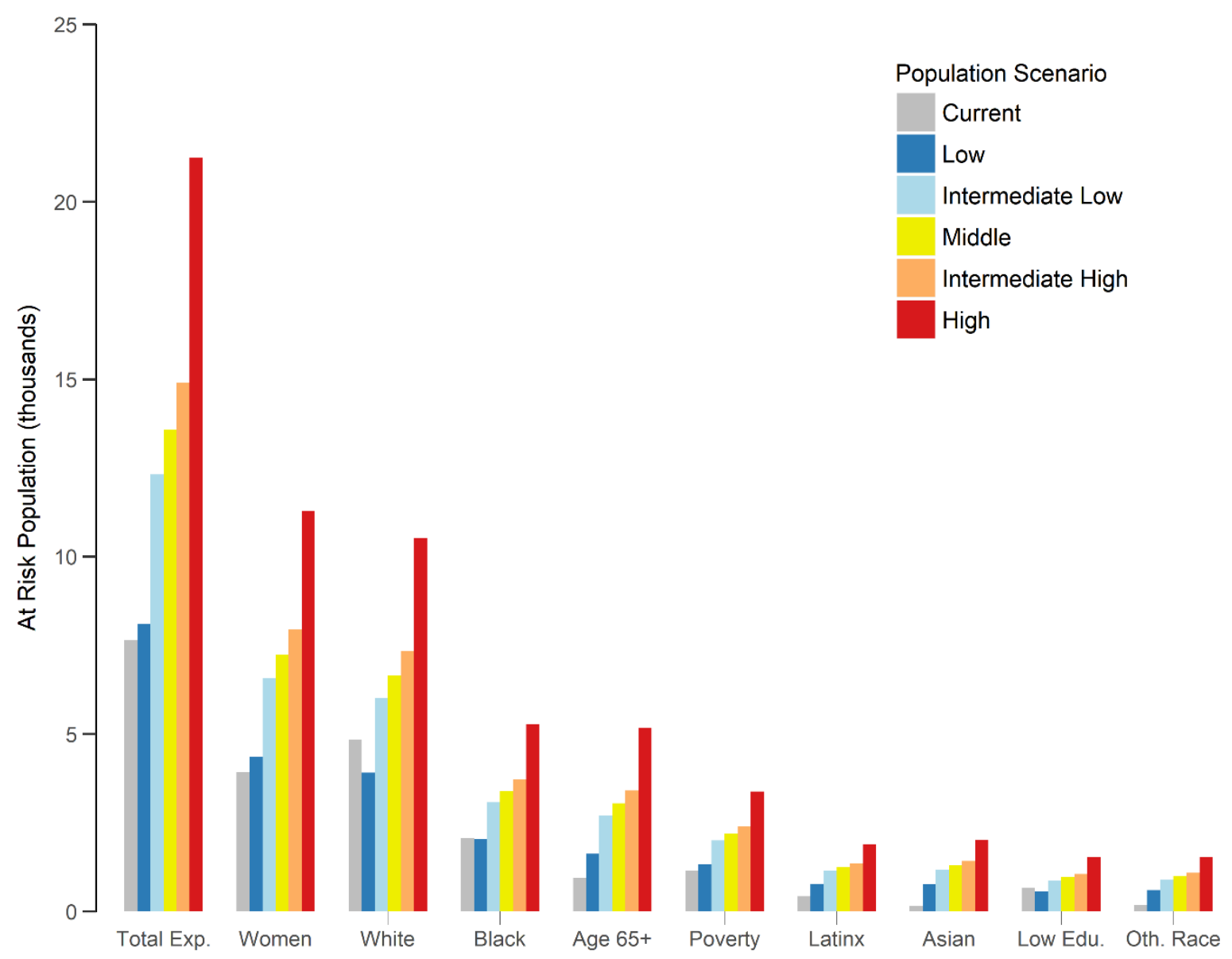

Figure S11. Absolute change in total and vulnerable sub-populations (including white subpopulation) to inundation exposure under the slow scenario for sea-level rise by 2050 . 


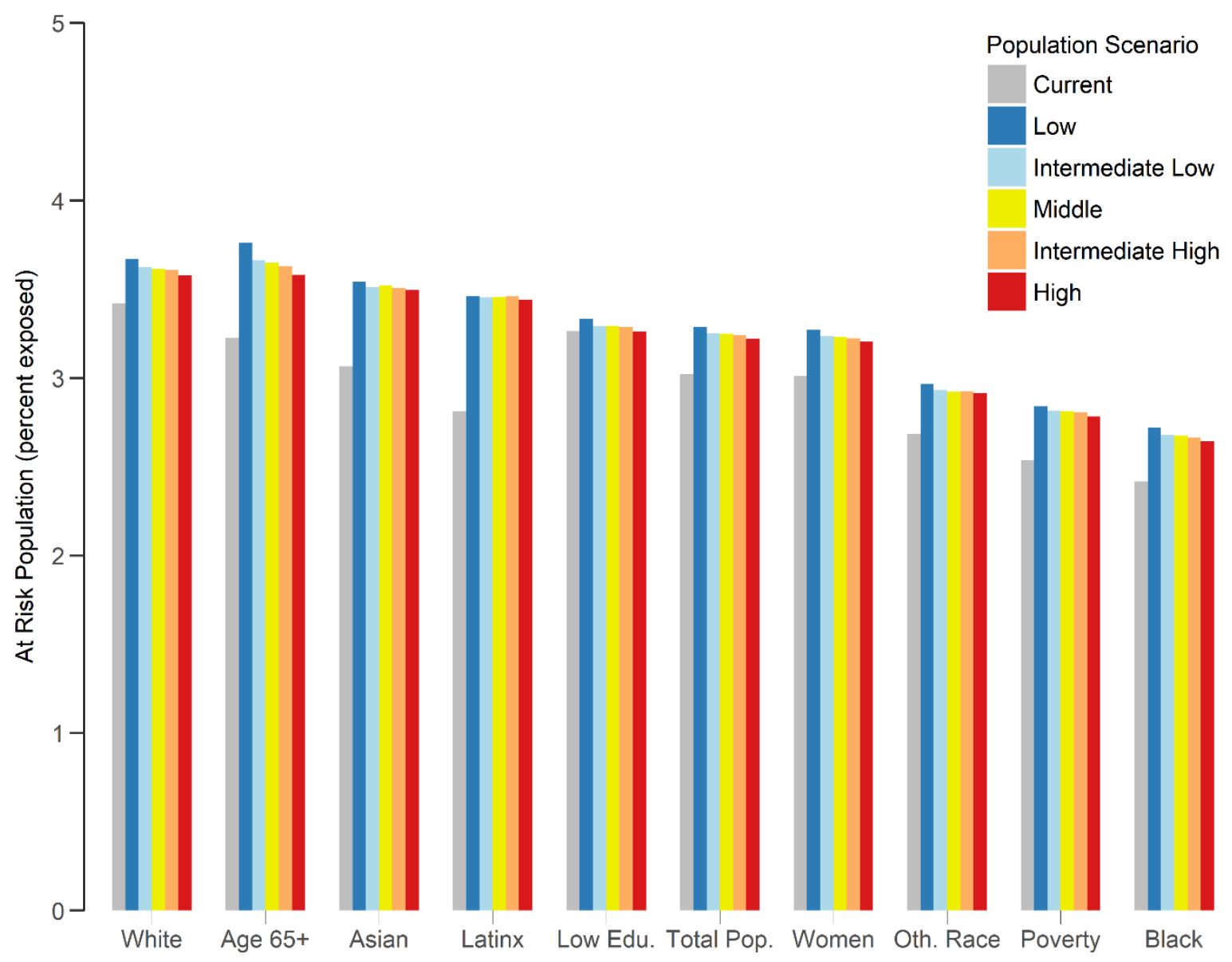

Figure S12. Proportional change in total and vulnerable sub-populations at risk (including white sub-population) to inundation exposure under the moderate scenario for sea-level rise by 2050 . 


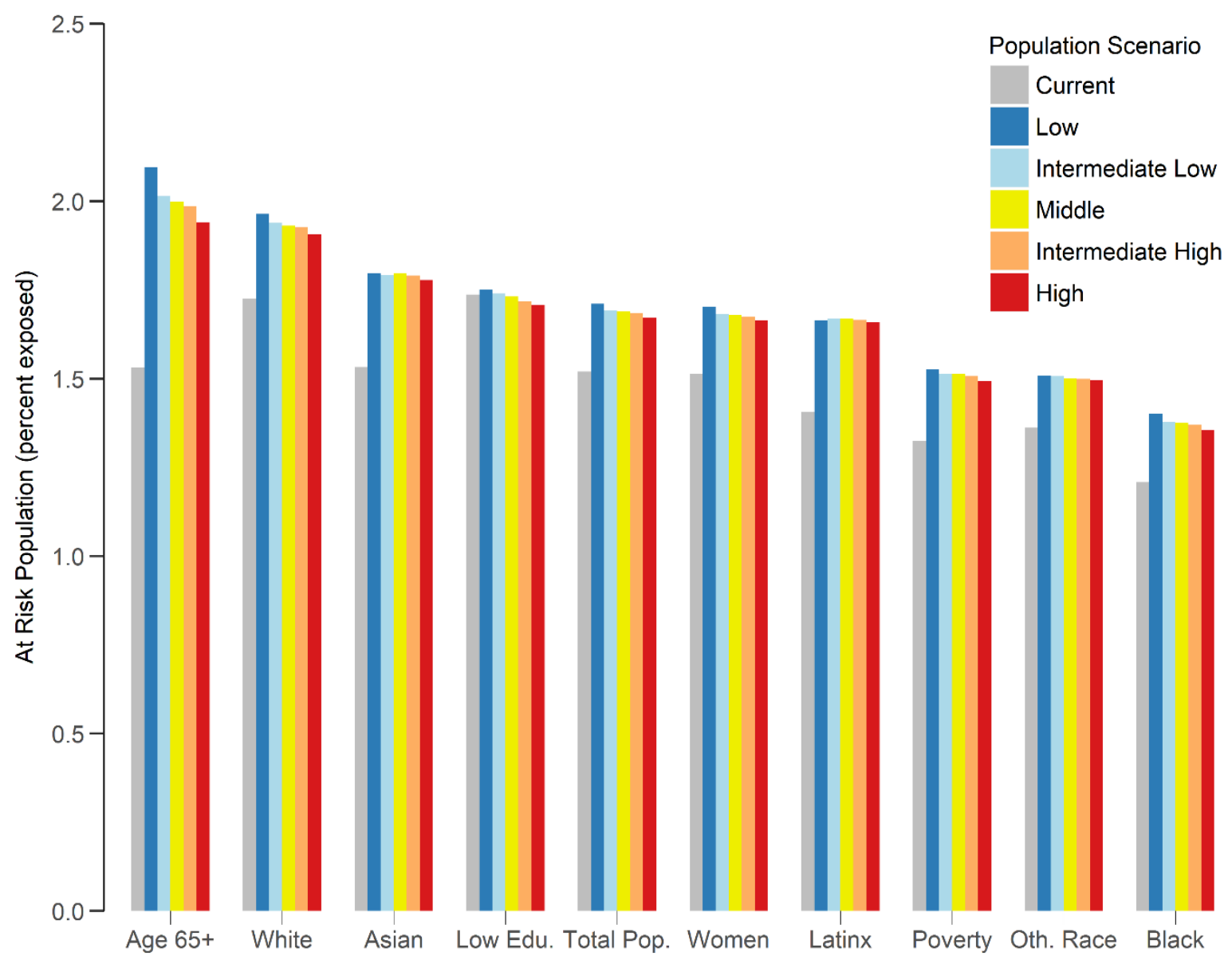

Figure S13. Proportional change in total and vulnerable sub-populations at risk (including white sub-population) to inundation exposure under the slow scenario for sea-level rise by 2050 . 